Revista General de Información y Documentación ISSN: $1132-1873$

http://dx.doi.org/10.5209/RGID.60811

\title{
Las administraciones locales como vigilantes del cumplimiento de la Ley de Transparencia por las entidades sin ánimo de lucro. Análisis del caso del Ayuntamiento de Barcelona
}

\author{
Pedro Molina Rodríguez-Navas; Nuria Simelio Solà; Vanessa Rodríguez Breijo ${ }^{3}$
}

Recibido: 10 de enero 2018 / Aceptado: 9 de mayo de 2018

Resumen. La aplicación de las nuevas obligaciones que establece la Ley de Transparencia a determinadas entidades no lucrativas presenta problemas operativos para su seguimiento y control. Sin embargo, la transparencia resulta fundamental para que estas organizaciones obtengan la confianza de sus públicos y para luchar contra la gestión ineficaz. El presente artículo realiza un estudio de caso sobre las entidades que han recibido subvenciones del Ayuntamiento de Barcelona en 2016 y que están obligadas a cumplir con la Ley de Transparencia de Cataluña. El objetivo es determinar si estas entidades están sujetas a la exigencia legal y si esta se cumple para permitir la rendición de cuentas a la ciudadanía. Para evaluar la transparencia de estas entidades se utiliza el proyecto TransparEnt ${ }^{4}$, una metodología propia y contrastada basada en una serie de indicadores que evalúan la calidad y transparencia de las informaciones. Por tanto, no se realiza un análisis jurídico de la ley de Transparencia, ni una valoración desde esta perspectiva, sino que partimos de establecer unos indicadores basados en la Ley de transparencia, para evaluar la información que se muestra en las webs de las entidades. Los resultados señalan que el Ayuntamiento de Barcelona tiene dificultades para realizar un correcto seguimiento de la transparencia de las entidades. En las conclusiones se propone la creación de estructuras compartidas de recursos y estrategias de formación y sensibilización para salvar la falta de tradición y conocimiento que padecen tanto las entidades como las administraciones públicas locales.

Palabras clave: transparencia; entidades no lucrativas; ONG; administraciones locales; administraciones públicas; subvenciones; comunicación digital; Internet; participación; rendición de cuentas.

1 Universitat Autònoma de Barcelona. Departamento de Periodismo y Ciencias de la Comunicación

E-mail: pedro.molina@uab.cat

2 Universitat Autònoma de Barcelona. Departamento de Periodismo y Ciencias de la Comunicación

E-mail: nuria.simelio.sola @uab.cat

3 Universidad de La Laguna. Departamento de Ciencias de la Comunicación y Trabajo Social

E-mail: vrbreijo@ull.edu.es

4 Página web del proyecto TransparEnt en http://transpar-ent.info/es (consulta 26/03/2018). El procedimiento de evaluación y la plataforma han sido desarrollados con el soporte de la Dirección General de Acción Cívica y Comunitaria de la Generalitat de Cataluña, de la Secretaria de Transparencia y Gobierno Abierto de la Generalitat de Cataluña y del Ayuntamiento de Barcelona. En noviembre de 2017 se ha presentado una variación de esta metodología adaptada a la Ley de Transparencia de la Comunidad Valenciana, que se ha publicado en una nueva plataforma web para que las entidades de Valencia la puedan utilizar como instrumento de autoevaluación. La plataforma se encuentra en http://valencia.transpar-ent.info (consulta 26/03/2018) y su desarrollo ha sido financiado por el Ayuntamiento de Valencia. 


\title{
[en] Local administrations as agents of enforcement of Transparency Law by non-profit organizations. Analysis of the Barcelona City Council case
}

\begin{abstract}
The application of the new obligations established by the Transparency Law to certain nonprofit organisations presents operational challenges for effective monitoring and control. However, for these organizations to gain the confidence of its stakeholders and to fight inefficient management, transparency is essential. This article presents a case study of the organisations that have received grants or public subsidies to the Barcelona City Council in 2016 are obliged to comply with the Law of Transparency of Catalonia. The principal aim is to determine if the organisations to which it grants subsidies are included among those that are subject to this legal requirement and if they really meet those requirements in order to allow the accountability of citizens. To evaluate transparency the TransparEnt project is used. This is an own and proven methodology based on a series of indicators that evaluate the quality and transparency of the information. Therefore, there is no legal analysis of the Transparency Law, nor an assessment from this perspective, but we start to establish indicators based on the Transparency Law, to evaluate the information displayed on the websites of the organisations. The principal results show the difficulties of the Barcelona City Council to correctly monitor the transparency of the organizations. The conclusions propose the creation of shared resource structures and the reinforcement of training and awareness strategies to overcome the lack of tradition, knowledge and resources that both non-profit organisations and local public administrations suffer from.
\end{abstract}

Keywords: Transparency; non-profit organisations; NGOs; local administrations; public administrations; subsidies; digital communication; Internet; participation; accountability.

Sumario. 1. Introducción. 2. Los beneficios de la transparencia para las entidades no lucrativas. 3. Objetivos y metodología. 4. Resultados. 5. Conclusiones y propuestas. 6. Referencias bibliográficas.

Cómo citar: Molina Rodríguez-Navas, P. Simelio Solà,N. Rodríguez Breijo, V. (2018) Las administraciones locales como vigilantes del cumplimiento de la Ley de Transparencia por las entidades sin ánimo de lucro. Análisis del caso del Ayuntamiento de Barcelona, en Revista General de Información y Documentación 28 (1), 61-93.

\section{Introducción}

Las entidades sin ánimo de lucro han de cumplir la Ley de Transparencia estatal ${ }^{5}$ y con otras de ámbito autonómico, dependiendo este deber de los importes recibidos a través de subvenciones u otros tipos de ayudas ${ }^{6}$ y del ámbito territorial de las administraciones que las conceden. En esta investigación analizamos las

5 Ley 19/2013, de 9 de diciembre, de transparencia, acceso a la información pública y buen gobierno. (BOE núm. 18, de 21 de enero de 2015), BOE, en https://www.boe.es/buscar/doc.php?id=BOE-A-2015-470. El artículo 3 de esta Ley recoge los supuestos en que las "entidades privadas" han de someterse a las obligaciones del Capítulo II sobre "Publicidad activa”. La Ley de Transparencia Cataluña en su artículo 3.4. también se refiere a "entidades privadas" sin considerar ninguna diferencia entre estas. Por tanto, no queda excluida ninguna tipología de entidad sin ánimo de lucro ni en marco normativo ni en el objeto de estudio de este trabajo. Para un análisis completo y pormenorizado de la Ley de transparencia puede consultarse a Wences, Kölling \& Ragone (2014) y Messeguer (2014).

6 La Ley de Transparencia de España, en el artículo 3.b., se refiere literalmente a “ayudas o subvenciones públicas” sin más concreción. Por tanto, consideraremos dentro de estas categorías cualquier aportación económica que reciba una entidad, bien sea a través de una convocatoria de subvenciones, una adjudicación directa, como resultado de un convenio de colaboración o por cualquier otra fórmula. La ley de Transparencia de Cataluña utiliza idénticos términos en el artículo 3.4. En el conjunto del texto nos referiremos a subvenciones y/o ayudas públicas englobando cualquier tipología de recurso económico recibido. 
dificultades que tiene el Ayuntamiento de Barcelona para determinar qué entidades deben cumplir con esta obligación y realizamos un análisis de la transparencia en las webs de las entidades que han recibido ayudas del mismo Ayuntamiento de Barcelona, a partir de la metodología TransparEnt. Por tanto, no se realiza un análisis jurídico sobre la aplicación de la Ley de Transparencia, ni se parte de esa perspectiva, sino que se aplica una metodología que considera la Ley para establecer si las entidades obligadas cumplen unos criterios mínimos para rendir cuentas ante la ciudadanía y la administración pública.

La metodología TansparEnt surge con el objetivo de facilitar una herramienta útil para la ciudadanía y para las administraciones, a causa de la dificultad existente tanto para determinar qué entidades están obligadas y cuáles no lo están, como para valorar si publican de forma completa y adecuada las informaciones correspondientes.

En este momento, las administraciones públicas pueden conceder subvenciones a entidades que cuando las solicitan garantizan que están cumpliendo con la legislación sobre transparencia que les afecta, pero que en realidad no lo están haciendo. Este problema es especialmente difícil de afrontar para las administraciones locales, como el Ayuntamiento de Barcelona, el caso que estudiamos en este trabajo.

La complicación es fruto de diferentes motivos. Por una parte, la norma estatal es de obligado cumplimiento para las entidades no lucrativas que reciben más de $100.000 €$ de ayudas o subvenciones (art. 3.b.), sumando los importes recibidos de las diferentes administraciones públicas. Pero, la falta de un fichero unificado donde conste qué entidades reciben diferentes ayudas públicas y cuáles son las cantidades otorgadas, no permite a las administraciones locales saber a qué entidades deben exigir el cumplimiento más que cuando las ayudas económicas que ellas mismas han concedido ya superan esa cantidad. Además, la falta de tradición de transparencia hace que el mismo organismo, como por ejemplo una administración local, pueda dar diferentes ayudas por diferentes conceptos a las mismas entidades sin que conste cuál es el importe total concedido a cada entidad jurídica, porque no se han establecido los mecanismos administrativos para que esto sea posible ${ }^{7}$.

En segundo lugar, la Ley también afecta a las entidades que reciben más de $5.000 €$ de subvenciones o ayudas en la misma anualidad, siempre que esas cantidades percibidas sean al menos el $40 \%$ de su presupuesto anual (art. 3.b.). En este segundo caso, aún es más complicado para las administraciones locales saber cuándo las entidades deben cumplir y cuáles no tienen esas obligaciones, puesto que, además de la cuestión ya explicada en el párrafo anterior, deben conocer el

\footnotetext{
La Base de Datos Nacional de Subvenciones (BDNS, Ministerio de Hacienda y Función Pública, Gobierno de España, en http://www.infosubvenciones.es/bdnstrans/es/index), publica las resoluciones de subvenciones de las administraciones públicas, incluidas las locales, cumpliendo con la finalidad de promoción de la transparencia que le asigna el Artículo 20 de la Ley 38/2003, de 17 de noviembre, General de Subvenciones (BOE núm. 276, de 18 de noviembre de 2013) - BOE, en https://www.boe.es/buscar/act.php?id=BOE-A2003-20977 -, pero ni ejecuta cruces de datos de forma automatizada ni dispone de herramientas para que los usuarios puedan hacerlos.
} 
presupuesto anual de la entidad y saber cuál es el porcentaje de este que suponen las subvenciones o ayudas recibidas. Dado que las administraciones municipales no tienen esta información, les resulta casi imposible saber qué entidades deben cumplir y cuáles no tienen esas obligaciones.

Estos mismos criterios los recogen las leyes autonómicas, que además pueden contemplar otros casos o pueden determinar nuevas obligaciones, lo que aún añade más problemas para que los ayuntamientos puedan saber qué entidades están obligadas y a qué. Por ejemplo, en algunas regiones, como en la Comunidad Valenciana, la ley propia ${ }^{8}$ no añade ninguna obligación nueva, pero sí incorpora otro grupo de sujetos obligados, ya que las personas jurídicas privadas que perciban en una anualidad ayudas o subvenciones por importe superior a $10.000 €$, deben publicar al menos la información relativa a estas concesiones (art. 3.b.2.). En cambio, la Ley de Cataluña ${ }^{9}$ recoge exactamente las mismas condiciones de la Ley estatal, pero incorpora más obligaciones para las organizaciones afectadas.

Por otra parte, las leyes de las diferentes autonomías solo son de aplicación considerando las subvenciones recibidas de las administraciones de la propia comunidad, desde las del Gobierno autonómico hasta las locales, por lo que puede darse el caso de entidades con sede en una comunidad que no han de cumplir con la Ley autonómica pero sí con la estatal, por ejemplo, en los casos en que se reciben subvenciones exclusivamente de administraciones del estado.

Por último, evaluar el cumplimiento de la Ley de transparencia no es fácil ni rápido. Esta ley es considerada como la más importante para las administraciones públicas españolas desde el inicio de la etapa constitucional porqué constituye una transformación radical desde la tradicional opacidad de la administración pública española a una legislación que permite superar este déficit democrático (Fernández y Pérez, 2014). Esta falta de tradición en la aplicación de la transparencia y el buen gobierno en las administraciones públicas provocan que sea necesario disponer de una metodología que contemple tanto aspectos cuantitativos, sobre las informaciones publicadas, como cualitativos, sobre las características de las publicaciones hechas respecto a factores como la comprensibilidad de las informaciones o la facilidad de acceso a las mismas.

Como hemos explicado, esta investigación surge como consecuencia de la existencia de ese problema y lo que nos proponemos fundamentalmente es mostrar su dimensión y características para poder ofrecer en las conclusiones un acercamiento a las soluciones.

Considerando estas dificultades, hemos estudiado el caso del Ayuntamiento de Barcelona como muestra ejemplificadora para determinar la magnitud del problema. Se trata de un Ayuntamiento muy importante, capital de una comunidad autónoma con Ley de Transparencia propia que aumenta las exigencias de la Ley

8 Ley 2/2015, de 2 de abril, de Transparencia, Buen Gobierno y Participación Ciudadana de la Comunitat Valenciana. (BOE núm. 100, de 27 de abril de 2015), BOE, en https://boe.es/buscar/act.php?id=BOE-A-2015$4547 \& \mathrm{p}=20160511 \& \mathrm{tn}=2$.

9 Ley 19/2014, de 29 de diciembre, de transparencia, acceso a la información pública y buen gobierno. Comunidad Autónoma de Cataluña. (BOE núm. 18, de 21 de enero de 2015), BOE, en http://www.boe.es/buscar/act.php?id=BOE-A-2015-470. 
estatal y donde tienen su sede entidades de toda tipología jurídica, ámbito de actuación y alcance territorial. A pesar de los grandes recursos con que cuenta esa administración y de que el marco legal es plenamente vigente, el Ayuntamiento de Barcelona no tiene resuelto el procedimiento para determinar qué entidades deben cumplir con la Ley de Transparencia y para saber si lo están haciendo.

La realización de esta investigación parte de considerar que, a pesar de estas dificultades, es imprescindible que las entidades que reciben financiación pública sean transparentes, porque la ciudadanía tiene derecho a saber quién recibe los recursos económicos públicos, para qué fines se utilizan y de qué manera son utilizados. Igualmente, consideramos que la transparencia es un valor que mejora la confianza que las entidades proyectan hacia la sociedad y que, por tanto, puesto que su incorporación les supone un beneficio, deben ser los primeros interesados en producir una comunicación cuyo eje central sea la transparencia.

\section{Los beneficios de la transparencia para las entidades no lucrativas}

Las entidades no lucrativas han gozado tradicionalmente de una buena aceptación por parte de la ciudadanía y, según las diferentes encuestas publicadas por organismos internacionales, se encuentran entre las organizaciones de la sociedad mejor valoradas (Herranz, 2007: 7). Sin embargo, su falta de transparencia ha permitido la proliferación de casos de corrupción o mala gestión que están en la base de un descenso de la credibilidad de la que antes gozaban. Burger \& Owens (2010) explican que precisamente el tercer sector está pasando en la actualidad por una crisis de transparencia que ha socavado su credibilidad.

De acuerdo con el barómetro de confianza de la consultora Edelman de 2015, las ONGs contaban con un $63 \%$ de confianza, hecho que destacaba en contraste con los datos que obtienen los medios de comunicación (47\%), empresas (43\%) y gobiernos (26\%). Pero en el barómetro de 2017 la confianza en las entidades no gubernamentales caía al mismo nivel que la confianza en los negocios y se situaba solo en el 53\% (Edelman, 2015; Edelman, 2017).

En este sentido, la transparencia y la responsabilidad corporativa pueden beneficiar claramente a estas organizaciones para mejorar la confianza de la ciudadanía. Esto también les permitiría mejorar las probabilidades de financiación y de obtención de recursos humanos (voluntariado), así como de cooperación con otras entidades y sujetos. En palabras de Martín Pérez y Martín Cruz (2017: 168): "la transparencia es un factor fundamental para que las organizaciones sin fines de lucro generen confianza, se legitimen ante la sociedad y creen las condiciones necesarias para favorecer su sostenibilidad”.

Como advierten Nos \& Santolino (2015), las organizaciones que aspiran a cambios sociales no pueden basar su comunicación solamente desde una perspectiva comercial o de promoción de una marca institucional, sino que esta debe basarse en una estrategia que identifique los objetivos sociales que pretenden lograr y que sea adecuada y coherente con los logros y mejoras que quieren conseguir para la sociedad. En esta misma línea, Navajo (2009) también defiende 
que la planificación estratégica de las entidades no lucrativas no puede utilizar las mismas herramientas que otras organizaciones o empresas y que deben basar su comunicación en la diferenciación esencial a través de los valores.

El riesgo de una deficiente gestión de la comunicación explica Fernández Torres (2007), es la generación de problemas que dificultan la consecución de los objetivos que persiguen estas entidades. Por el contrario, una comunicación adecuada y abierta con sus diferentes públicos servirá para que logren el apoyo público para una actividad, causa o movimiento, consiguiendo más fácilmente los fines que se proponen. García-López (2012) señala además que las entidades han de ofrecer un modelo de comunicación con la ciudadanía más abierto, horizontal y deliberativo. Pero destaca, al mismo tiempo, que el principal obstáculo para ello es la opacidad con la que estas reflejan su estructura y funcionamiento, a la vez que el bloqueo, parcial o total, del acceso a la información sobre esos aspectos. Para García-López (2012) el objetivo de dar voz a la ciudadanía no puede entenderse sin la apertura de canales de acceso a la información, tanto para el control de la gestión de los proyectos, como para el surgimiento de un discurso crítico que permita corregir los desvíos o déficits de esas entidades y que visibilice sus logros y resultados.

Por tanto, las organizaciones no lucrativas deben seguir una política de comunicación interna y externa que les permita mostrar sus principios y acciones de forma transparente. Desde esta perspectiva, la comunicación facilita la creación y el mantenimiento de alianzas sólidas entre las entidades y sus socios, simpatizantes y la ciudadanía en general (Arroyo, Baladrón \& Martín, 2013: 1). Además, el uso de la web y las redes sociales les permite hacer una estrategia de comunicación amplia, pese al número limitado de recursos humanos y materiales que generalmente tienen, y desarrollar una vía directa de relación con la ciudadanía, para desarrollar otras acciones y conseguir más donaciones y voluntarios. Sin embargo, en el marco español estas organizaciones todavía no utilizan todas las oportunidades que les brinda la web social en relación con la transparencia y la comunicación (Arroyo, Baladrón \& Martín, 2013: 8).

En los casos específicos en que las entidades del tercer sector han utilizado Internet y las redes sociales para conseguir la movilización y la concienciación ciudadana, se ha mostrado que la comunicación digital ha tenido éxito y se ha conseguido un aumento de la confianza en estas entidades y mayor participación cívica. Esto se muestra en el estudio realizado por Baamonde, Martínez \& Mínguez (2016: 90) sobre la campaña \#dereitos365.

En este sentido, Barranquero (2014) defiende que el modelo actual de comunicación que todavía domina en muchas organizaciones debe ser reformulado para dar paso a un nuevo sistema mucho más transparente y que entienda la comunicación como un "espacio de empoderamiento y promoción de la cultura de la cooperación y la movilización ciudadanas” (Barranquero, 2014: 6). Gaventa \& McGee (2013) también consideran que exigir y garantizar la rendición de cuentas es un camino hacia el empoderamiento de las personas, o al menos hacia una mayor eficacia para responder a las necesidades y las voces de aquellos a quienes dicen servir. Este aspecto también es resaltado por Darnton \& Martin (2011), que 
advierten a las entidades no gubernamentales anglosajonas que deben transformar sus viejas estructuras y su relación con la ciudadanía para conseguir sus objetivos de cambio social. Esta apertura de la transparencia permitiría aumentar el compromiso de los socios y participantes con la organización, pues con ella representan mejor los valores compartidos (Martín Pérez \& Martín Cruz, 2017).

La rendición de cuentas de las organizaciones se puede clasificar según los colectivos a los que se dirija la información. Puede ser ascendente si va dirigida a los donantes, descendente, si llega a los beneficiarios e interna, cuando concierne al personal y otros implicados en la misión. Un error común de las organizaciones es brindar información especialmente hacia donantes y patrocinadores, dejando en segundo plano a los otros colectivos (Martín Pérez \& Martín Cruz, 2017). Al respecto, Darnton \& Martin (2011) destacan que es urgente que las entidades sean menos jerárquicas y que es necesario que muestren una mayor responsabilidad y transparencia porque deben dar ejemplo para conseguir ser vistas como honestas y fiables. Además, recuerdan que el público joven es cada vez más crítico ante las estructuras que consideran tradicionales, como las entidades no gubernamentales, y que estos utilizan Internet y los medios no tradicionales para conseguir información, realizando campañas propias utilizando la red social. Por tanto, es trascendental este cambio interno de las entidades para que puedan sobrevivir a la nueva situación (Darnton \& Martin, 2011: 110-116).

La transparencia y la rendición de cuentas se han posicionado durante el último decenio como elementos clave para luchar contra los fracasos del desarrollo y los déficits democráticos. En este sentido el e-gobierno es un concepto innovador que tiene un potencial enorme para el presente y el futuro de las entidades públicas, promoviendo y permitiendo una mayor transparencia, rendición de cuentas y responsabilidad pública (Vargas, 2011). Una mayor rendición de cuentas previene y repara la corrupción y la ineficiencia, consiguiendo que la ayuda y el gasto público se canalicen más eficazmente y con ello aumentan las iniciativas de desarrollo, sus resultados y su visibilidad (Gaventa \& McGee, 2013). Al respecto, Gálvez, Caba \& López (2016), en un estudio sobre las ONGs en Colombia, destacan que, en contextos de corrupción de las organizaciones del tercer sector, donde la ciudadanía ha perdido la confianza en estas, Internet y la transparencia se han convertido en los elementos más eficaces para conseguir una mayor eficiencia y una mejor relación con su público objetivo.

Aunque hay teorías que plantean que las entidades no lucrativas tienden a gestionarse de manera más honesta que las organizaciones con fines de lucro, la notoria falta de transparencia del sector, su escaso monitoreo efectivo, la regulación más laxa por parte del Estado, el atractivo de la exención de impuestos y la naturaleza subjetiva e intangible de los servicios y bienes que proporcionan, constituyen argumentos para pensar que lo opuesto también podría ser cierto (Burger \& Owens, 2010).

Además, a diferencia del sector con fines de lucro, en el que la elección del consumidor ayuda a proporcionar retroalimentación, y a diferencia también del ámbito público, en el que la gestión ineficaz de un político puede castigarse votando por uno de sus oponentes, en el sector sin fines de lucro no existen 
mecanismos análogos de feedback. Los beneficiarios no pueden votar en contra de las ONG explotadoras o corruptas, ni castigar a las organizaciones poco confiables o que presentan comportamientos inadecuados. Estos argumentos sugieren que existen amplias oportunidades para el engaño y la ineficacia entre las ONG debido a la asimetría de información y el dilema del riesgo moral en sus relaciones con benefactores y beneficiarios (Burger \& Owens, 2010).

De manera que, al igual que las corporaciones y gobiernos, las entidades no lucrativas no son infalibles y la disponibilidad oportuna de información confiable es esencial para su regulación efectiva y la supervisión de su gestión por parte de beneficiarios, donantes y entidades gubernamentales. De esta forma, la transparencia es concebida como un reconocimiento de que los sistemas no son perfectos y que necesitan controles y balances para que los posibles errores y equivocaciones puedan ser identificados y rectificados (Burger \& Owens, 2010). Así, la transparencia aminora los conflictos de intereses y la mala gestión de los recursos (Szper \& Prakash, 2011), ya que constituye un potente mecanismo de señalización.

Por ello, las organizaciones sin fines de lucro deben comunicar información relacionada con su viabilidad financiera, conformidad legal tanto externa como interna, coste de los servicios prestados y, no menos importante, actuación de sus gestores, que deberá ser evaluada en términos de eficacia y eficiencia (Martín Pérez \& Martín Cruz, 2017). La transparencia no solo requiere rendir cuentas, sino que incluye también mostrar abiertamente el engranaje de una organización: cómo funciona, cómo realiza su trabajo, cuáles son los procesos internos, sus decisiones o los resultados obtenidos. Las cuestiones referidas a la rendición de cuentas y la transparencia suelen ser entendidas de una manera simplista, como sinónimo de justificación hacia los entes que otorgan financiación, sin tener en cuenta la responsabilidad con los propios beneficiarios y la información sobre el impacto que han tenido las acciones sobre los procesos de desarrollo (Baamonde-Silva, GarcíaMirón \& Martínez-Rolán, 2017).

La rendición de cuentas entendida de esta forma promueve en las entidades un esfuerzo constante para mejorar y, de esta manera, no quedar excluidas de los circuitos de financiación obtenida en concurrencia competitiva (Martín Pérez \& Martín Cruz, 2017). María Pilar Dopazo (2012) afirma, en el ámbito de la rendición de cuentas sobre Responsabilidad Social Corporativa, que esta permite una evaluación relativa entre los distintos sujetos/operadores, ya sean de una misma rama o de diferentes sectores, para conocer su nivel de compromiso y que la disponibilidad de esa información es cada vez más valorada por los mercados, pues permite tanto una autoevaluación como una evaluación por parte de terceros. Es, además, una manera de profundizar en la comunicación con todos los grupos de interés de una organización y una declaración pública de compromiso

Desde esta perspectiva, la transparencia no puede ser entendida en su versión limitada y basándose solo en el marco legal, sino que como explica Martínez (2011) debe abrirse un debate sobre si esta racionalidad administrativa se ha impuesto como único elemento de transparencia y ha provocado que se alejen de una comunicación honesta y seria que permita que pongan la mirada en "en su 
capacidad para promover, alentar o reforzar procesos de cambio social, cuyos protagonistas son otras personas y otros colectivos en otras sociedades” (Martínez, 2011: 20).

La sinceridad que implica esta rendición de cuentas, explica Santolino-Prieto (2010), es valorada positivamente por los distintos públicos de las organizaciones. La necesidad de fondos, de mostrar una gestión económica eficaz, o avances en la reducción de los índices de pobreza y desigualdad no pueden ocultar los errores, las dificultades y los conflictos, pues estos son consecuencia de la gran complejidad ética y técnica que conlleva el trabajo de cooperación. Y todos los donantes deberían conocer estos datos. "Explicar por qué algo no ha funcionado y cómo se está aprendiendo de la experiencia es algo que la opinión pública puede apreciar especialmente” (Santolino-Prieto, 2010: 246).

Así, la transparencia y la rendición de cuentas son, ante todo, un acto de responsabilidad de las propias acciones. Las organizaciones evalúan y comunican sus logros, sus fallos y sus planes de mejora, y todo ello tiene una influencia en la percepción que se tiene sobre ella en la sociedad. No se trata solo de un informe, es un proceso, y, como tal, debe estar definido en al menos tres aspectos: ¿a quién rendir cuentas?, si a la asamblea, a los equipos directivos, a los usuarios, a las entidades colaboradoras o a la sociedad; ¿quién debe rendir cuentas?, si la junta directiva, el equipo directivo, la sede central u otra dependencia; y ¿cómo se debe rendir cuentas?, es decir, precisar los mecanismos, los niveles y las herramientas que va a emplear en dicho proceso (Arredondo Trapero, Garza García \& Vázquez Parra, 2014).

Sin embargo, a pesar de la definición de estos aspectos podría resultar que la organización rindiera cuentas sobre algún asunto en cuestión, pero no fuera transparente en las demás áreas. Por ello, la transparencia va más allá de la rendición de cuentas (Arredondo Trapero, Garza García \& Vázquez Parra, 2014) y existe en la medida en que una organización libre y universalmente proporciona información completa sobre todos sus atributos, pero también mantiene una comunicación oportuna directamente con todas las audiencias públicas clave (LaPorte, Demchak, \& DeJong 2002).

Además, para el cumplimiento de la ley de transparencia sea efectiva, las entidades sin ánimo de lucro deben también tener en cuenta los siguientes aspectos planteados por Villoria (2014) para las instituciones gubernamentales, pero que creemos que se pueden aplicar a todo tipo de entidades (Villoria, 2014: 63-64): tener un sistema de archivos y almacenaje de decisiones eficaz; una simplificación exigente de normas y procedimientos, una interoperabilidad eficaz entre los sistemas o componentes para intercambiar la información, una garantía de agilidad en la provisión en la provisión de información y en su tratamiento y renovación, un sistema de incentivos al cumplimiento, un sistema eficaz de sanciones de los incumplimientos, y un presupuesto suficiente. Por otro lado, es deseable que los datos publicados puedan ser reutilizados para no restringir su acceso y su uso. Algunos de los aspectos que permiten esta reutilización son: una simple notificación que indique claramente la situación legal para estos datos o 
documentos, acceso a los datos de forma gratuita y unos formatos de publicación adecuados que sean claros y de libre acceso (Álvarez, 2014: 37-38).

De forma que consideramos imprescindible que las entidades cumplan, al menos, con las obligaciones legales. Sin embargo, la falta de tradición y de prácticas de administración desarrolladas y consolidadas, dificultan que las administraciones públicas de España que otorgan financiación a estas organizaciones conozcan si realmente lo hacen. En este trabajo, hacemos un estudio que consideramos de utilidad tanto para las entidades no lucrativas como para dichas administraciones, clarificando las dificultades del problema con el análisis de un caso revelador.

\section{Objetivos y metodología}

\subsection{Objetivos}

En esta investigación se realiza un estudio de caso, sobre el Ayuntamiento de Barcelona, con dos objetivos principales.

El primero es conocer qué entidades que han recibido ayudas o subvenciones públicas en 2016 están obligadas a cumplir con la Ley de Transparencia de Cataluña y el estado de la transparencia de esas entidades. Es decir, saber si publican las informaciones y si lo hacen de forma adecuada para cumplir con la Ley de Transparencia y para que la ciudadanía tenga conocimiento de cómo son utilizados los recursos públicos. Esto se hace a partir de una metodología propia, el proyecto TransparEnt que evalúa una serie de indicadores basados en los requisitos de la Ley de Transparencia y en los criterios que deben tener las webs para ofrecer una información de calidad. En este sentido, el objetivo no es realizar un estudio jurídico sobre la Ley de Transparencia, sino realizar una evaluación de las webs de las entidades a partir de unos indicadores que tienen en cuenta un abanico amplio de cuestiones relacionadas con la transparencia y la comunicación.

El segundo es determinar qué dificultades afronta el Ayuntamiento de Barcelona para saber si las entidades, a las que otorga subvenciones u otras ayudas económicas, deben cumplir con la Ley de Transparencia de Cataluña y si realmente la cumplen.

Los resultados de este caso, dadas las características del sujeto estudiado, permitirán obtener unas conclusiones que se puedan extender al conjunto de municipios de Cataluña y de España.

El objetivo se fundamenta y es coherente considerando la vigencia de la Ley de Transparencia de Cataluña en 2016 y que en las Bases de la convocatoria de subvenciones para proyectos, actividades y servicios del Ayuntamiento de Barcelona en 2016 ${ }^{10}$, apartado “16. Obligaciones de los/de las

10 Bases reguladores per a atorgar subvencions per a la realització de projectes, activitats i serveis de districte $i$ de ciutat de l'Ajuntament de Barcelona. BOPB 27/10/2015, en http://ajuntament.barcelona.cat/sites/default/files/bases_2016.pdf. Traducciones de este documento y de la "Declaración responsable” de los autores. 
beneficiarios/beneficiarias", se puede leer que una de estas obligaciones es: "Dar cumplimiento a la Ley 19/2014, de 29 de diciembre, de transparencia, acceso a la información pública y buen gobierno en los términos en que le sea aplicable” (p. 9). Consecuentemente, en el "Documento básico 1" que las entidades ha de entregar para concurrir a la convocatoria, titulado "Solicitud de subvención al Ayuntamiento de Barcelona ICUB/IBE/IMD para la realización de proyectos, actividades y servicios de distrito y de Ciudad”, en el apartado "3. Declaración responsable del Presidente/a de la entidad o persona que ostente la representación del solicitante", uno de los puntos que declara la persona firmante es: "Que cumple la Ley 19/2014, de 29 de diciembre, de transparencia, acceso a la información pública y buen gobierno en los términos en que le sea aplicable”.

\subsection{Metodología}

Para alcanzar los objetivos, hacemos un estudio sobre las entidades que reciben subvenciones y ayudas públicas del Ayuntamiento de Barcelona, a partir de los datos ofrecidos por el propio Ayuntamiento en su página web, en la que se encuentra la resolución definitiva de la Convocatoria general de subvenciones para proyectos, actividades y servicios de distrito y de ciudad de $2016^{11}$. En primer lugar, realizamos un traslado de los datos a una hoja Excel, y se ordenaron por categorías útiles para este estudio, que determinan cuántas entidades recibieron subvenciones en esa convocatoria, su naturaleza jurídica y las cuantías de dichas subvenciones. Trabajamos los datos de esa convocatoria por la relevancia que tiene entre las entidades sin ánimo de lucro de la ciudad.

A continuación, descargamos de la web del Ayuntamiento de Barcelona los datos sobre el conjunto de subvenciones y ayudas otorgadas, y los analizamos para contrastar estos datos con los anteriores sobre la Convocatoria General. Una vez obtenida esta información, sumamos los importes recibidos del Ayuntamiento de Barcelona por cada entidad y por diferentes conceptos. Para hacer este trabajo, el día 23 de octubre de 2016 descargamos el archivo "2016_subv" en formato XLSX, de la página del Ayuntamiento de Barcelona Open Data $B C N^{12}$. Este archivo contiene la relación completa de subvenciones y transferencias del Ayuntamiento de Barcelona y de las entidades municipales en 2016 hasta esa fecha, en un total de 4.237 filas, una por cada concesión económica.

El paso siguiente fue obtener información sobre las subvenciones concedidas por la Generalitat de Catalunya a las mismas entidades en el mismo año, para saber cuál es el importe total de ayudas que han recibido esas organizaciones de todas las administraciones públicas de Cataluña. Ese cruce de datos lo realizamos con las subvenciones y ayudas otorgadas por los tres organismos de la Generalitat de Catalunya que se ocupan principalmente de las entidades sin ánimo de lucro: la Dirección General de Acción Cívica y Comunitaria, la Secretaria de Deportes y la Dirección General de Cultura Popular. Intentamos primero obtener los datos en la

\footnotetext{
11 Descargada de http://ajuntament.barcelona.cat/ca/informacio-administrativa/subvencions

12 Disponible en http://opendata.bcn.cat/opendata/ca/catalog/TRANSFERENCIAS\#.
} 
web de la institución, pero no fue posible encontrarlos en el momento en que los precisábamos o bien estaban en la web, pero en formatos con los que no era posible trabajar. De forma que contactamos con cada uno de los organismos para solicitar la información en documentos como CSV, Excel o similares. En todos los casos fueron atendidos nuestros requerimientos.

Una vez ordenado el listado de entidades que habían recibido subvenciones del Ayuntamiento de Barcelona y complementado con las recibidas por las mismas entidades de la Generalitat de Cataluña, tomamos como muestra de evaluación las 55 entidades que recibieron las mayores cuantías, todas ellas por encima de $200.000 €$ en esa anualidad.

Para evaluar su transparencia utilizamos los indicadores y criterios del proyecto TransparEnt ${ }^{13}$ porque nos permite valorar tanto la presencia de las informaciones como el cumplimiento con dos principios de transparencia básicos: la inteligibilidad de las informaciones y su facilidad de acceso (Molina, 2017). De esta forma, consideramos tanto elementos de evaluación cuantitativa como cualitativa, tales como si las informaciones se publican de forma comprensible y accesible. El procedimiento recoge las exigencias de la Ley de Transparencia estatal y las de la Ley de Transparencia de Cataluña que, como ya se ha dicho, es más exigente que la española. Además, se incluyen algunas cuestiones relativas a la publicación de las informaciones y para conseguir que realmente con su publicación se consiga una mayor participación.

Esta metodología adapta el diseño de metodologías que se prepararon y pusieron a prueba anteriormente para la evaluación de las páginas web de las administraciones públicas locales (Moreno, Molina y Simelio, 2017; Molina, Simelio y Corcoy, 2017). Desde esa perspectiva, planteada como auditoria cívica de la transparencia de las administraciones públicas, en la que se concede gran importancia a los aspectos comunicativos, se elaboró una relación de indicadores para la evaluación de la transparencia de las entidades sin ánimo de lucro, contrastando los requerimientos de la legislación y otros métodos específicamente diseñados para el caso de las entidades no lucrativas. Algunos de estos habían sido publicados en manuales para entidades (Fernández y Ospina, 2012; Valls, 2010), otros en documentos técnicos (Coordinadora, 2012) y, finalmente, también se utilizó como referente el procedimiento de la Fundación Lealtad, publicado en su página web ${ }^{14}$.

La relación de indicadores resultante se sometió a la valoración de un grupo de 96 representantes de entidades mediante una encuesta. Considerando las respuestas de estos se realizaron modificaciones y se publicó una guía (Molina, 2014).

13 Página web del proyecto TransparEnt en http://transpar-ent.info/es (consulta 26/03/2018). El procedimiento de evaluación y la plataforma han sido desarrollados con el soporte de la Dirección General de Acción Cívica y Comunitaria de la Generalitat de Cataluña, de la Secretaria de Transparencia y Gobierno Abierto de la Generalitat de Cataluña y del Ayuntamiento de Barcelona. En noviembre de 2017 se ha presentado una variación de esta metodología adaptada a la Ley de Transparencia de la Comunidad Valenciana, que se ha publicado en una nueva plataforma web para que las entidades de Valencia la puedan utilizar como instrumento de autoevaluación. La plataforma se encuentra en http://valencia.transpar-ent.info (consulta 26/03/2018) y su desarrollo ha sido financiado por el Ayuntamiento de Valencia.

14 Fundación Lealtad en http://www.fundacionlealtad.org/web/home (consulta 26/03/2018). 
Finalmente, se hicieron algunas modificaciones para la publicación del procedimiento también como metodología de autoevaluación, fruto ya de la experiencia de las primeras aplicaciones y para aprovechar las posibilidades de la web para ofrecer relaciones de indicadores diferenciadas por tipologías de entidades.

Esta metodología permite evaluar de forma diferente 4 tipologías de entidades: (I) asociaciones y clubes deportivos; (II) fundaciones; (III) federaciones y entidades de nivel superior; y (IV) cualquier otra tipología de entidad no lucrativa no incluida en las tres categorías anteriores, tales como como entidades religiosas, cooperativas, entidades informales, etc. De este modo, se hace una evaluación que considera características diferentes, como pueden ser los órganos de gobierno propios de cada tipología jurídica, la posibilidad o no de tener personas asociadas, etc. Así, se utilizan 45 indicadores para evaluar las tipologías I, II y IV, pero la tipología II se analiza con 44 indicadores, ya que el indicador 3.11 sobre la convocatoria de asambleas en las organizaciones no puede exigirse en el caso de las fundaciones ya que estas no cuentan con personas asociadas y, por tanto, no se realizan asambleas. El resto de las diferencias en el redactado de los indicadores responden al interés por especificar de la forma más concreta posible la información que se demanda en cada caso, pero las informaciones a publicar son básicamente iguales. La relación de indicadores se completa con otra de criterios asociados a cada indicador para conseguir que la evaluación se realice con el máximo de objetividad.

Por otra parte, el procedimiento está dividido en 4 escalones, cada uno más exigente que el anterior. Esto permite ver si las informaciones que se encuentran responden a criterios informativos y de transparencia o si se han publicado sin tener criterios claros. Por otra parte, esta división en escalones permite ofrecer la metodología a las entidades para que puedan autoevaluarse y disponer de un procedimiento de mejora, que tienen disponible en la web del proyecto TransparEnt.

A continuación, ofrecemos como muestra la relación de indicadores de la tipología IV, que para el resto sufre modificaciones, como ya se ha indicado. La numeración de los indicadores responde a una división en 5 bloques de información: 1, la entidad; 2, órganos y personas que gestionan y/o forman la entidad; 3, cómo se gestiona la entidad; 4 , cómo se informa sobre la entidad; y 5 , procedimientos de participación. Todos los indicadores tienen la misma valoración para el resultado del análisis, de forma que se suma el total de indicadores validados y se obtiene un porcentaje sobre el total.

\section{Escalón 1.}

1.1 ¿Se publican el nombre y los signos distintivos gráficos de la entidad?

1.2 ¿Se informa sobre la forma jurídica de la entidad?

1.3 ¿Se publica información sobre la misión, la visión y los valores de la entidad? 
1.4 ¿Se publica información sobre cuáles son las personas o los colectivos que pueden ser miembros, beneficiarios o usuarios?

1.5 ¿Se publica información sobre la creación e historia de la entidad?

1.6 ¿Se informa sobre las sedes de la entidad y la atención al público?

2.1 ¿Se publica información sobre cuáles son los órganos de gobierno?

2.2 ¿Se publica información sobre las funciones de los cargos que forman los órganos de gobierno?

2.3 ¿Se publica información sobre las personas que forman parte de los órganos de gobierno?

3.1 ¿Se informa de si la entidad es miembro o colabora con otras organizaciones públicas o privadas?

5.1 ¿Se informa del procedimiento a seguir para ser socio, voluntario o colaborador?

Escalón 2.

1.7 ¿Se publican los estatutos?

1.8 ¿Se publica información sobre los aspectos más destacados de los estatutos?

2.4 ¿Se publica un correo electrónico de contacto de cada una de las personas que forman parte de los órganos de gobierno?

2.5 ¿Se publica información sobre la trayectoria de las personas que forman parte de los órganos de gobierno?

2.6 ¿Se publica información estadística sobre voluntarios y otras personas vinculadas a la entidad?

3.2 ¿Se informa sobre la periodicidad con que se reúnen los órganos de gobierno?

3.3 ¿Se publica información sobre cuál es el marco legal que regula el funcionamiento de la entidad?

3.4 ¿Se publica información sobre otros documentos internos que regulan el funcionamiento de la entidad?

3.5 ¿Se publica el presupuesto anual?

3.6 ¿Se publica información sobre el origen de los ingresos?

3.7 ¿Se da información sobre qué parte del presupuesto se dedica a la ejecución de proyectos y actividades relacionadas con la misión de la entidad?

4.1 ¿Se publican noticias sobre la entidad y sobre las decisiones tomadas en las asambleas y demás órganos de gobierno?

5.2 ¿Se informa de las actividades que pueden desarrollar los socios o voluntarios y de cómo pueden participar?

5.3 ¿Se informa sobre la existencia de espacios de participación como grupos de trabajo, comisiones u otros?

Escalón 3.

2.7 ¿Se informa de si las personas que forman parte de los órganos de gobierno reciben retribuciones por trabajos prestados a la entidad?

2.8 ¿Se publica información sobre el organigrama ejecutivo y/o técnico? 
2.9 ¿Se informa sobre la existencia de un consejo asesor o de otros asesores, ¿quiénes son y si son retribuidos?

3.8 ¿Se publica información sobre la planificación del año en curso?

3.9 ¿Se publican las cuentas anuales del último ejercicio finalizado y las auditorías, en su caso?

$3.10 \dot{¿}$ Se informa sobre el cumplimiento de las obligaciones tributarias y con la Seguridad Social?

3.11 ¿Se publican las convocatorias y el orden del día de las asambleas con suficiente antelación?

3.12 ¿Se publica un plan estratégico?

4.2 ¿Se publica el nombre de la persona encargada de la comunicación de la organización y su contacto?

$4.3 \dot{¿}$ Se hacen en las web campañas de publicidad y/o se publican los materiales utilizados en otros soportes para difundir las actividades o captar socios, voluntarios, etc.?

$5.4 \dot{¿}$ Se publican los enlaces a las redes sociales de la entidad?

5.5 ¿Se informa de las condiciones en que se ejerce el voluntariado?

Escalón 04

2.10 ¿Se publica información sobre el equipo de dirección/gestión y el equipo técnico?

3.13 ¿Se publica información de seguimiento de los proyectos vigentes?

3.14 ¿Se publica información que permita valorar la calidad de los servicios y el grado de cumplimiento de los objetivos generales de la entidad y de sus proyectos?

3.15 ¿Se publican informes de seguimiento del presupuesto anual?

3.16 ¿Se publican las retribuciones de los máximos responsables de la gestión de la entidad y el convenio colectivo que regula las condiciones de trabajo del personal contratado?

$4.4 \dot{¿}$ Se publica una agenda de actividades?

$4.5 ¿$ ¿Se informa sobre la existencia de una política de transparencia?

5.6 ¿Hay un buzón virtual de sugerencias y quejas?

\section{Resultados}

\subsection{Convocatoria general anual del Ayuntamiento de Barcelona}

\subsubsection{Subvenciones de ciudad, de la convocatoria general, por ámbitos temáticos}

En primer lugar, presentamos las subvenciones otorgadas en la Convocatoria general para actuaciones de ciudad por ámbitos temáticos (Tabla 1). 
Tabla 1. Convocatoria general de subvenciones para proyectos, actividades y servicios de distrito y de ciudad 2016, subvenciones de ciudad por ámbitos temáticos.

\begin{tabular}{|c|c|c|c|c|c|c|}
\hline Ámbito & $\begin{array}{l}\mathrm{N}^{0} \\
\text { total } \\
\text { sub. }\end{array}$ & $\begin{array}{c}\text { Sub. } \\
>100.0 \\
00 €\end{array}$ & $\begin{array}{c}\text { Sub. } \\
\text { entre } \\
5.000 \\
\mathbf{y} \\
100.00 \\
€ \\
\end{array}$ & $\begin{array}{c}\% \text { de } \\
>5.000 € \\
\text { sobre } \\
\text { total }\end{array}$ & $\begin{array}{c}>5000 €: \\
\text { entidades no } \\
\text { lucro / total } \\
\text { entidades }\end{array}$ & $\begin{array}{c}>5.000 €, \mathbf{n}^{\circ} \\
\text { de } \\
\text { entidades } \\
\text { no lucro } \\
\text { por clave } \\
\text { NIF* }\end{array}$ \\
\hline SALUD & 221 & 0 & 23 & 10,41 & $23 / 23$ & 22G, 1R \\
\hline $\begin{array}{l}\text { ECO- } \\
\text { URBANISMO }\end{array}$ & 65 & 0 & 7 & 10,77 & $7 / 7$ & $5 \mathrm{G}, 2 \mathrm{~F}$ \\
\hline COMERCIO & 173 & 0 & 69 & 39,88 & $68 / 69$ & $\begin{array}{c}\text { 56G; 11F, } \\
1 \mathrm{~V}\end{array}$ \\
\hline $\begin{array}{l}\text { PARTICIPACIÓN } \\
\text { CIUDADANA }\end{array}$ & 214 & 0 & 12 & 5,61 & $11 / 12$ & $11 \mathrm{G}$ \\
\hline CULTURA & 328 & 1 & 150 & 46,04 & $87 / 151$ & $\begin{array}{c}82 \mathrm{G}, 4 \mathrm{~F}, \\
1 \mathrm{~V}\end{array}$ \\
\hline DEPORTES & 128 & 4 & 53 & 44,53 & $45 / 57$ & $45 G$ \\
\hline DISCAPACIDAD & 27 & 0 & 19 & 70,37 & $19 / 19$ & $17 \mathrm{G}, 2 \mathrm{~F}$ \\
\hline Total & 1.156 & 5 & 333 & $29,24 \%$ & 260/338 & $\begin{array}{c}238 \mathrm{G}, 19 \mathrm{~F}, \\
1 \mathrm{R}, 2 \mathrm{~V}\end{array}$ \\
\hline
\end{tabular}

Clave NIF de las entidades no lucrativas según Agencia Tributaria del Gobierno de España en Orden EHA/451/2008, en www.agenciatributaria.es/static_files/ AEAT/Contenidos_Comunes/La_Agencia_Tributaria/Segmentos_Usuarios/Empres as_y_profesionales/NIF/NIFEntidades99.pdf

$\mathrm{F}=$ sociedades cooperativas.

$\mathrm{G}=$ asociaciones, federaciones, fundaciones, partidos políticos, sindicatos, organizaciones empresariales y otras asociaciones.

$\mathrm{R}=$ congregaciones e instituciones religiosas.

$\mathrm{V}=$ otros no definidos.

Como se puede ver en la Tabla 1, sólo 5 subvenciones superan los 100.000€, 4 del sector deporte y 1 del sector cultura.

Por otra parte, las subvenciones superiores a 5.000€ (incluyendo las superiores a $100.000 €$ ) solo suponen el $29,24 \%$ del total de subvenciones concedidas. Sin embargo, hay diferencias importantes por sectores: en el ámbito de la discapacidad se concede un número menor de subvenciones respecto a otros, pero más del 70\% de estas superan los 5.000€; por el contrario, en otros ámbitos el número de subvenciones es mayor que en el de discapacidad, pero las que superan los $5.000 €$ son muy pocas, como es el caso del ámbito salud (10,41\%) o, especialmente, participación ciudadana (5,61\%). 
Gráfico 1. Subvenciones de ciudad por ámbitos

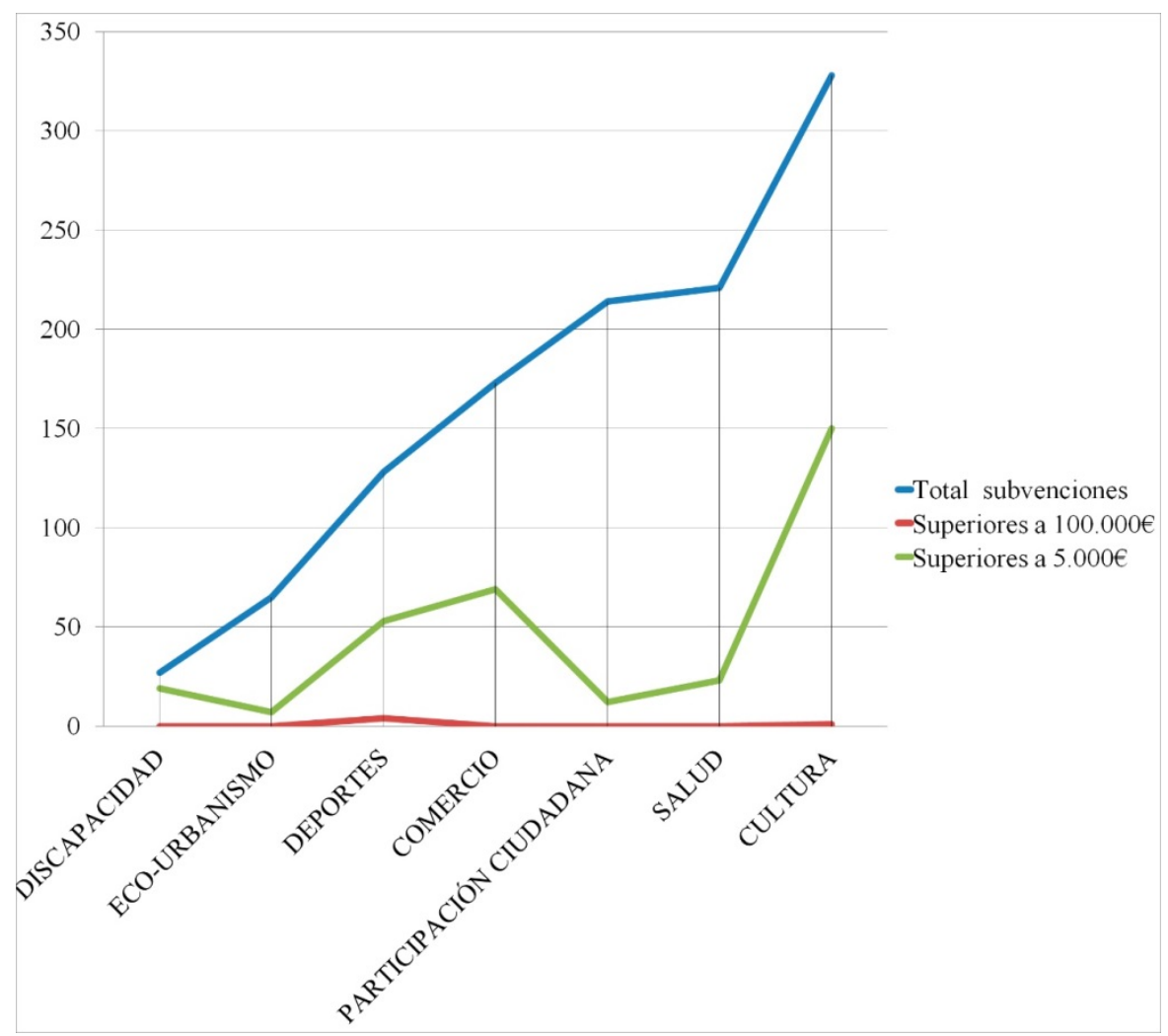

Los datos de la Tabla 1, representados en el Gráfico 1, muestran que no hay una relación directa entre el número de subvenciones otorgadas y las cuantías que implican obligaciones de transparencia. En algunos ámbitos hay una proporción más estrecha que en otros. Hay un diferencial especialmente marcado en Participación Ciudadana y también en Salud y Eco-Urbanismo.

Este dato podría hacer suponer que no son numerosas las entidades que estarían afectadas por la Ley de Transparencia, pero recordemos que en esta primera aproximación aún no se han sumado las diferentes subvenciones concedidas a una misma entidad.

También podemos ver en la Tabla 1 que de las 338 subvenciones concedidas de más de 5.000€, 260 lo han sido a entidades sin ánimo de lucro. Esta cifra representa el 76,92\% del total, por lo tanto, más de tres cuartas partes. En los ámbitos de cultura y, especialmente, deportes, hay una proporción significativa de subvenciones otorgadas a otros tipos de organizaciones.

Por último, de entre las entidades sin ánimo de lucro subvencionadas con $5.000 €$ o más, una parte muy mayoritaria (238 de 260) tienen la clave G en su NIF $\mathrm{y}$, por tanto, son principalmente asociaciones, federaciones o fundaciones. 


\subsubsection{Subvenciones para actuaciones de distrito de la convocatoria general}

Tabla 2. Convocatoria general, subvenciones para actuaciones de distrito

\begin{tabular}{|c|c|c|c|}
\hline Distrito & $\begin{array}{c}\mathrm{N}^{\mathrm{o}} \mathrm{de} \\
\text { subvenciones }\end{array}$ & $\begin{array}{c}\text { Superiores a } \\
100.000 €\end{array}$ & $\begin{array}{c}\text { Superiores a } \\
5.000 €\end{array}$ \\
\hline Ciutat Vella & 67 & 0 & 1 \\
\hline Eixample & 63 & 0 & 3 \\
\hline Sants-Montjuic & 121 & 0 & 6 \\
\hline Les Corts & 19 & 0 & 1 \\
\hline Sarria-Sant Gervasi & 24 & 0 & 2 \\
\hline Gràcia & 58 & 0 & 3 \\
\hline Horta-Guinardó & 70 & 0 & 1 \\
\hline Nou Barris & 31 & 0 & 7 \\
\hline Sant Andreu & 129 & 0 & 5 \\
\hline Sant Martí & 93 & 0 & 8 \\
\hline Total & 675 & 0 & 37 \\
\hline
\end{tabular}

\subsection{Ayudas y subvenciones otorgadas en 2016}

Tal y como se especifica en la página de la que se descargaron los datos ${ }^{15}$ (23 de octubre de 2016), estas ayudas y subvenciones pueden ser otorgadas por cuatro motivos: mediante convocatorias de subvenciones $y$ ayudas en régimen competitivo, de forma directa a un ente privado, a través de un convenio o vinculadas a una concesión.

En la Tabla 3 se recoge el número de entidades que reciben estas ayudas, según la clave del NIF, con la finalidad de diferenciar las que son entidades sin ánimo de lucro, objeto de estudio de esta investigación.

Con esta clasificación, se puede apreciar que de las 4.237 ayudas concedidas, las correspondientes a entidades no lucrativas son 3.223, el 76,0\% del total. De estas, la parte mayoritaria, con mucha diferencia, son las entidades con clave $G$ en su NIF (2.983), mientras que las claves F, R y V, tienen valores muy similares, entre 74 y 87 entidades que reciben ayudas.

Para definir completamente cuáles de estas entidades se corresponden con nuestro objeto de estudio y cuáles no, hemos diferenciado las diferentes tipologías de ayudas concedidas a las entidades con llave $G$, tal y como se mencionan en el mismo documento. 
Tabla 3. Tipologías de entidades que reciben ayudas según la clave de su NIF

\begin{tabular}{|c|c|c|}
\hline Clave NIF & $\mathrm{N}^{0}$ de ayudas & $\begin{array}{c}\mathrm{N}^{0} \text { de ayudas } \\
\text { agrupando claves }\end{array}$ \\
\hline $\begin{array}{l}\text { No consta (premios, convenios de cooperación } \\
\text { educativa y otros) }\end{array}$ & 306 & \multirow{2}{*}{384} \\
\hline $\begin{array}{l}\text { K (anticipos de caja, urgencias y otros } \\
\text { Ayuntamiento de Barcelona) }\end{array}$ & 78 & \\
\hline $\begin{array}{l}\text { Entidades extranjeras sin clave o con claves: } \\
\text { BE, DE, DK, GB, MZ, N, NL, PO, VR y W. }\end{array}$ & 18 & 18 \\
\hline P (corporaciones locales) & 44 & \multirow{3}{*}{213} \\
\hline Q (organismos públicos) & 161 & \\
\hline $\begin{array}{l}\text { S (órganos de la administración del estado y las } \\
\text { comunidades autónomas) }\end{array}$ & 8 & \\
\hline A (sociedades anónimas) & 45 & \multirow{5}{*}{399} \\
\hline B (sociedades de responsabilidad limitada) & 324 & \\
\hline E (comunidades de bienes) & 2 & \\
\hline J (sociedades civiles) & 12 & \\
\hline U (uniones temporales de empresas) & 16 & \\
\hline F (sociedades cooperativas) & 87 & \multirow{4}{*}{3.223} \\
\hline $\begin{array}{l}\text { G (asociaciones, federaciones, fundaciones, } \\
\text { partidos políticos, sindicatos, organizaciones } \\
\text { empresariales y otras asociaciones). }\end{array}$ & 2.983 & \\
\hline R (congregaciones e instituciones religiosas) & 79 & \\
\hline V (otros no definidos) & 74 & \\
\hline
\end{tabular}

Tabla 4. Tipologías de las ayudas concedidas a las entidades con NIF clave G

\begin{tabular}{|c|c|c|}
\hline Tipologías de las ayudas & $\mathrm{N}^{0}$ de ayudas & $\begin{array}{c}\begin{array}{c}\text { Consideradas en } \\
\text { el estudio }\end{array} \\
\end{array}$ \\
\hline Concesiones & 61 & Sí \\
\hline Convenios cooperación educativa & 6 & No \\
\hline Convocatorias y ayudas & 2.514 & Sí \\
\hline Subvenciones directas & 140 & Sí \\
\hline $\begin{array}{l}\text { Subvenciones a entes públicos y entidades } \\
\text { participadas }\end{array}$ & 18 & $\begin{array}{l}\text { Parcialmente: } 9 \text { sí, } \\
9 \text { no }\end{array}$ \\
\hline Subvenciones por convenio & 229 & Sí \\
\hline $\begin{array}{l}\text { Transferencias a entes públicos y entidades } \\
\text { participadas }\end{array}$ & 15 & $\begin{array}{l}\text { Parcialmente: } 5 \text { sí, } \\
10 \text { no }\end{array}$ \\
\hline
\end{tabular}

La revisión de estos datos ha llevado a desestimar para el estudio los 6 convenios de cooperación educativa y 19 de las ayudas concedidas a entes públicos y entidades participadas, por tratarse de grupos políticos, sindicatos, pago de cuotas u otras circunstancias especiales. Por tanto, hechas las correcciones señaladas en la 
columna derecha, el número final de entidades con clave G que se consideran en el estudio es de 2.958 .

En el grupo de entidades con clave $\mathrm{V}$ también se han descartado tres ayudas concedidas como "Transferencias a entes públicos y entidades participadas”, por los mismos motivos que se ha hecho en el caso de las entidades con llave G. Por lo tanto, estas entidades pasan a ser de 74 a 71.

Tabla 5. Cuantías de las ayudas otorgadas a las entidades con NIF clave G (2.958 entidades)

\begin{tabular}{|l|c|c|}
\hline \multicolumn{1}{|c|}{ Cuantías } & \multirow{2}{*}{$\mathbf{N}^{\mathbf{0}}$ de ayudas } & \multirow{2}{*}{ \% } \\
\cline { 1 - 2 } Extraordinarias: una de 3.223.617€ y otra de 2.880.000€ & 2 & \multirow{2}{*}{25,25} \\
\cline { 1 - 2 } Entre 500.000 y 750.000€ & 47 & \multirow{2}{*}{72,99} \\
\hline Entre 100.000 y 499.999,99€ & 747 & \\
\hline Entre 5.000 y 99.999,99€ & 2.157 & \\
\cline { 1 - 2 } Menores de 5.000€ & 2 & \\
\cline { 1 - 2 } Importe negativo &
\end{tabular}

El 72,99\% de las ayudas concedidas a entidades con llave G son de menos de $5.000 €$ y sólo el $1,76 \%$ superan los $100.000 €$, según se muestra en la Tabla 5. Por el contrario, de las 52 ayudas que superan esa cantidad, algunas son de cuantías muy elevadas, que llegan a superar los 3.000.000€. El 25,25\% de las ayudas o subvenciones se encuentran entre 5.000 y $100.000 €$.

En las Tablas siguientes (6, 7 y 8), presentamos los mismos datos pero referidos a las entidades con claves F, R y V. En los tres casos, el número de ayudas es mucho más bajo, pero en porcentaje las ayudas más importantes, por encima de 100.000€, son más numerosas que en el caso de las entidades con clave G.

Es especialmente evidente en el caso de las cooperativas (F), donde el 11,49\% recibe subvenciones de más de $100.000 €$, que llegan hasta los $425.000 €$, y el 26,44\% recibe ayudas de entre 5.000 y $100.000 €$.

Por el contrario, las entidades religiosas $(\mathrm{R})$ son las que presentan un mayor porcentaje de ayudas de menos de 5.000€, aunque las que se encuentran en el corte más alto, por encima de $100.000 €$, son el 6,33\%.

Tabla 6. Cuantías de las ayudas otorgadas a las entidades con NIF clave F (87 entidades)

\begin{tabular}{|l|c|c|}
\hline \multicolumn{1}{|c|}{ Cuantías } & $\mathbf{N}^{\mathbf{0}}$ de ayudas & $\mathbf{\%}$ \\
\hline Entre 136.833,52 y 425.000,00€ & 10 & 11,49 \\
\hline Entre 5.000 y 99.999,99 & 23 & 26,44 \\
\hline Menores de 5.000€ & 54 & 62,07 \\
\hline
\end{tabular}


Tabla 7. Cuantías de las ayudas otorgadas a las entidades con NIF clave R (79 entidades)

\begin{tabular}{|l|c|c|}
\hline \multicolumn{1}{|c|}{ Cuantías } & $\mathbf{N}^{\mathbf{0}}$ de ayudas & $\mathbf{\%}$ \\
\hline Entre 183.333,48 y 279.450,00€ & 5 & 6,33 \\
\hline Entre 5.000 y 99.999,99 & 13 & 16,46 \\
\hline Menores de 5.000€ & 61 & 77,22 \\
\hline
\end{tabular}

Tabla 8. Cuantías de las ayudas otorgadas a las entidades con NIF clave V (71 entidades)

\begin{tabular}{|l|c|c|}
\hline \multicolumn{1}{|c|}{ Cuantías } & $\mathbf{N}^{\mathbf{0}}$ de ayudas & \% \\
\hline Entre 123.248,00 y 194.400,00€ & 3 & 4,23 \\
\hline Entre 5.000 y 99.999,99€ & 23 & 32,39 \\
\hline Menores de 5.000€ & 45 & 63,38 \\
\hline
\end{tabular}

Gráfico 2. Porcentaje de ayudas recibidas por tramos de cuantías y clave NIF

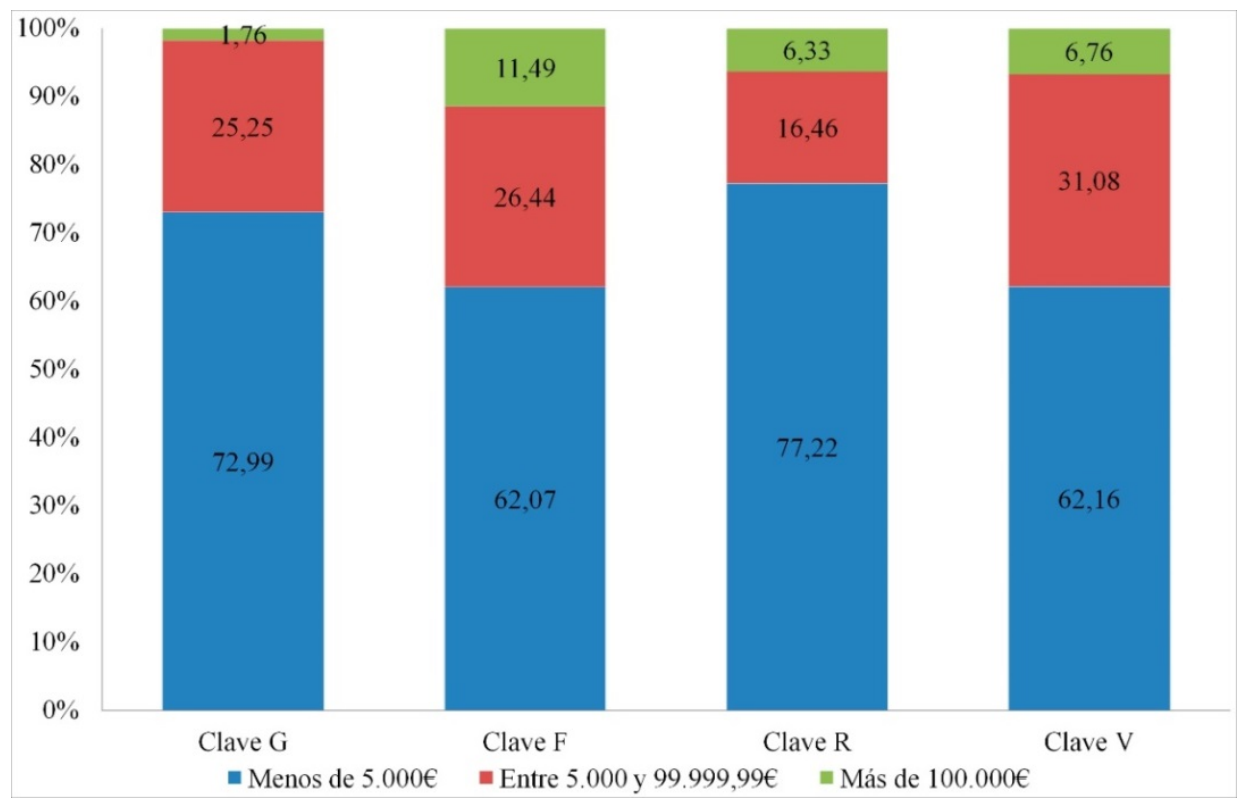

\subsection{Subvenciones y ayudas concedidas por el Ayuntamiento de Barcelona y la Generalitat de Catalunya}

Para determinar qué entidades están obligadas y cuáles no, a cumplir con la Ley de Transparencia de Cataluña, primero hemos agrupado las ayudas otorgadas por el Ayuntamiento de Barcelona para sumar todas las cantidades recibidas por una misma entidad y, a continuación, hemos añadido también las ayudas otorgadas por la Generalitat de Cataluña a estas entidades subvencionadas por el Ayuntamiento de Barcelona. 
Tabla 9. Subvenciones y/o ayudas concedidas por el Ayuntamiento de Barcelona a entidades sin ánimo de lucro, por cuantías, y entidades que han recibido subvenciones y/o ayudas del Ayuntamiento de Barcelona, por cuantías, sumando a esos importes las cantidades que estas mismas entidades han recibido de la Generalitat de Catalunya

\begin{tabular}{|l|c|c|}
\hline \multicolumn{1}{|c|}{ Cuantía } & $\begin{array}{c}\mathbf{N}^{\mathbf{0}} \mathbf{y} \text { \% subvenciones y/o } \\
\text { ayudas Ayuntamiento } \\
\text { Barcelona }\end{array}$ & $\begin{array}{c}\mathbf{N}^{\mathbf{0}} \mathbf{y} \text { \% entidades que } \\
\text { reciben ayudas } \\
\text { agrupadas Aj. Bcn. } \\
\text { más Gencat y \%. }\end{array}$ \\
\hline $\begin{array}{l}\text { Más hasta } 100.00 ~ \\
3.305 .617 €\end{array}$ & $82(2,2 \%)$ & $101 \quad(5,4 \%)$ \\
\hline Entre 5.000 y 99.999,99€ & $2.317(72,5 \%)$ & $693(37,2 \%)$ \\
\hline Menores de 5.000€ Total & 3.195 & $1.069(57,4 \%)$ \\
\hline \multicolumn{2}{r|}{} & 1.863 \\
\hline
\end{tabular}

Como se puede ver en la Tabla 9, una vez sumadas las cantidades recibidas por una misma entidad, podemos ver que 1.332 (3.195-1.863=1.332) ayudas otorgadas por el Ayuntamiento de Barcelona las reciben entidades que ya reciben otra u otras de la misma administración.

Aunque el 72,5\% de las ayudas concedidas por el Ayuntamiento de Barcelona no llegan a los 5.000€, una vez sumadas las cantidades recibidas por una misma entidad, tanto provenientes del propio Ayuntamiento como de la Generalitat de Cataluña, las entidades que no llegan a percibir $5.000 €$ en subvenciones representan el 57,4\% del total, un porcentaje significativamente más bajo que el anterior a dicha suma. Esto no descarta que algunas de estas puedan recibir otras subvenciones de otras administraciones públicas.

Gráfico 3. Porcentaje de ayudas y subvenciones otorgadas por el Ayuntamiento de Barcelona, por tramos de cuantías

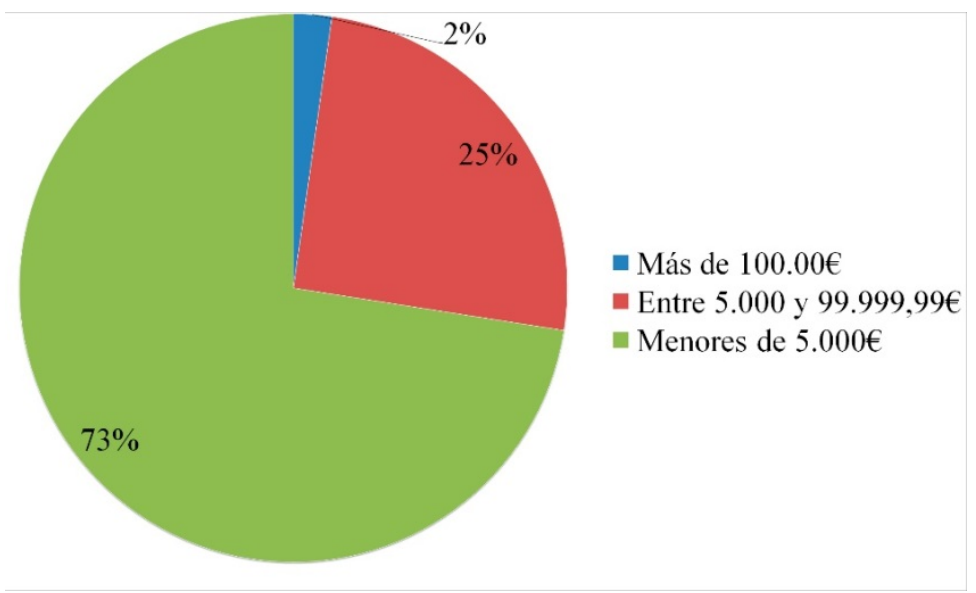


Gráfico 4. Porcentaje de entidades que reciben ayudas y subvenciones del Ayuntamiento de Barcelona, por cuantías, agrupando las cantidades recibidas del Ayuntamiento de Barcelona y de la Generalitat de Cataluña

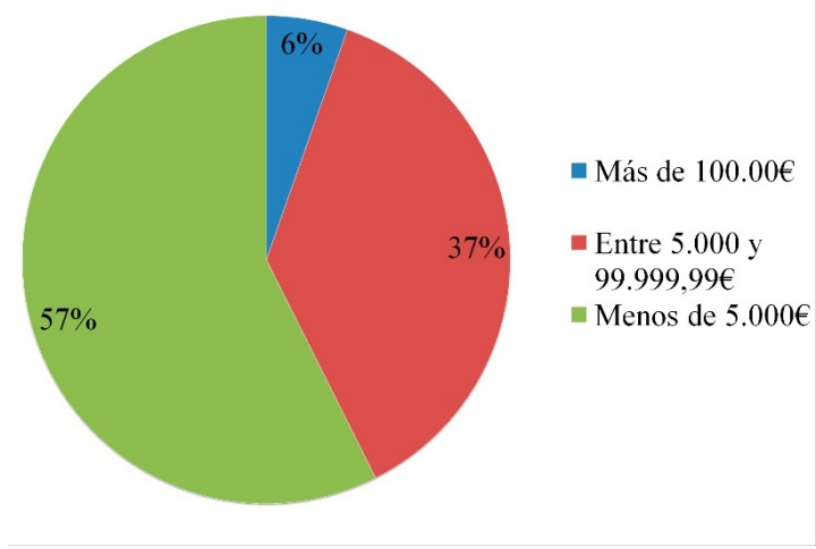

Por otra parte, 101 entidades reciben ayudas de más de $100.000 €$, una vez se ha hecho la suma de subvenciones recibidas, incorporando las provenientes de la Generalitat de Cataluña, mientras que antes de la misma eran 72.

En este mismo caso, el número de entidades que reciben ayudas de entre 5.000 y 99.999,99€; son 693, suponiendo un $37,2 \%$ del total. Por lo tanto, el $46,2 \%$ de las entidades que tienen estas subvenciones reciben más de $5.000 € \mathrm{y}$, en consecuencia, pueden estar obligadas a cumplir con la Ley de Transparencia. Antes de hacer esta suma de importes recibidos, los datos disponibles indicaban que las ayudas concedidas por encima de $5.000 €$ eran del $27,5 \%$, por tanto, hay una diferencia de casi veinte puntos porcentuales.

En la Tabla 10 mostramos el origen de las subvenciones o ayudas concedidas a las 12 entidades que reciben las cantidades más importantes. Esta relación permite ver la gran diversidad de casos posibles, desde entidades que solo reciben una subvención del Ayuntamiento de Barcelona (caso 12) o dos (caso 1 y caso 2), hasta otros que reciben hasta 18 ayudas del Ayuntamiento de Barcelona (caso 8). Otros, como el caso 6 o el caso 10, reciben una única y muy pequeña subvención del Ayuntamiento de Barcelona, pero tienen una financiación mayoritaria de la Generalitat de Cataluña, que en el caso 6 acaba superando el millón de euros. Por último, algunas entidades reciben ayudas de la administración local y de la autonómica de forma más equilibrada, como ilustra el caso 4. 
Tabla 10. Las 12 entidades que han recibido mayores cuantías, importes de las subvenciones o ayudas recibidas y origen

\begin{tabular}{|c|c|c|}
\hline Entidad & Administración que otorga & Importe \\
\hline \multirow[t]{2}{*}{1} & $\mathrm{AjBcn}$ & 3.223 .617 \\
\hline & $\mathrm{AjBcn}$ & 82.000 \\
\hline \multirow[t]{2}{*}{2} & $\mathrm{AjBcn}$ & 2.880 .000 \\
\hline & $\mathrm{AjBcn}$ & 200.000 \\
\hline \multirow[t]{11}{*}{3} & $\mathrm{AjBcn}$ & 425.000 \\
\hline & $\mathrm{AjBcn}$ & 221.464 \\
\hline & $\mathrm{AjBcn}$ & 199.484 \\
\hline & $\mathrm{AjBcn}$ & 192.700 \\
\hline & $\mathrm{AjBcn}$ & 165.582 \\
\hline & $\mathrm{AjBcn}$ & 139.798 \\
\hline & $\mathrm{AjBcn}$ & 136.834 \\
\hline & $\mathrm{AjBcn}$ & 79.230 \\
\hline & AjBcn & 65.634 \\
\hline & $\mathrm{AjBcn}$ & 30.062 \\
\hline & $\mathrm{AjBcn}$ & 900 \\
\hline \multirow[t]{14}{*}{4} & $\mathrm{AjBcn}$ & 279.450 \\
\hline & $\mathrm{AjBcn}$ & 230.337 \\
\hline & $\mathrm{AjBcn}$ & 199.436 \\
\hline & $\mathrm{AjBcn}$ & 183.333 \\
\hline & $\mathrm{AjBcn}$ & 49.021 \\
\hline & AjBcn & 40.448 \\
\hline & $\mathrm{AjBcn}$ & 38.628 \\
\hline & GenCat & 1.477 \\
\hline & GenCat & 3.437 \\
\hline & GenCat & 3.255 \\
\hline & GenCat & 12.976 \\
\hline & GenCat & 322.753 \\
\hline & GenCat & 6.521 \\
\hline & GenCat & 6.140 \\
\hline \multirow[t]{4}{*}{5} & $\mathrm{AjBcn}$ & 2.700 \\
\hline & GenCat & 5.183 \\
\hline & GenCat & 546.317 \\
\hline & GenCat & 770.342 \\
\hline \multirow[t]{5}{*}{6} & $\mathrm{AjBcn}$ & 400 \\
\hline & GenCat & 353.211 \\
\hline & GenCat & 643.776 \\
\hline & GenCat & 6.418 \\
\hline & GenCat & 3.870 \\
\hline \multirow[t]{5}{*}{7} & $\mathrm{AjBcn}$ & 15.000 \\
\hline & GenCat & 371.007 \\
\hline & GenCat & 606.904 \\
\hline & GenCat & 617 \\
\hline & GenCat & 3.009 \\
\hline
\end{tabular}




\begin{tabular}{|c|c|c|}
\hline \multirow[t]{18}{*}{8} & AjBcn & 11.437 \\
\hline & AjBcn & 2.700 \\
\hline & AjBcn & 16.356 \\
\hline & $\mathrm{AjBcn}$ & 2.923 \\
\hline & AjBcn & 616,51 \\
\hline & AjBcn & 180.945 \\
\hline & $\mathrm{AjBcn}$ & 121.946 \\
\hline & AjBcn & 104.333 \\
\hline & AjBcn & 94.000 \\
\hline & AjBcn & 87.444 \\
\hline & AjBcn & 83.402 \\
\hline & AjBcn & 67.237 \\
\hline & AjBcn & 56.250 \\
\hline & AjBcn & 40.663 \\
\hline & AjBcn & 40.649 \\
\hline & AjBcn & 20.331 \\
\hline & AjBcn & 14.574 \\
\hline & AjBcn & 1.505 \\
\hline \multirow[t]{26}{*}{9} & AjBcn & 217.830 \\
\hline & AjBcn & 19.600 \\
\hline & GenCat & 36.000 \\
\hline & GenCat & 36.000 \\
\hline & GenCat & 36.000 \\
\hline & GenCat & 7.500 \\
\hline & GenCat & 58.133 \\
\hline & GenCat & 40.000 \\
\hline & GenCat & 6.711 \\
\hline & GenCat & 11.104 \\
\hline & GenCat & 9.049 \\
\hline & GenCat & 6.711 \\
\hline & GenCat & 7.663 \\
\hline & GenCat & 6.711 \\
\hline & GenCat & 6.153 \\
\hline & GenCat & 6.949 \\
\hline & GenCat & 8.425 \\
\hline & GenCat & 8.425 \\
\hline & GenCat & 43.273 \\
\hline & GenCat & 42.142 \\
\hline & GenCat & 47.372 \\
\hline & GenCat & 60.000 \\
\hline & GenCat & 9.754 \\
\hline & GenCat & 8.425 \\
\hline & GenCat & 7.949 \\
\hline & GenCat & 12.357 \\
\hline \multirow[t]{3}{*}{10} & AjBcn & 431 \\
\hline & GenCat & 4.500 \\
\hline & GenCat & 10.000 \\
\hline
\end{tabular}




\begin{tabular}{|l|l|r|}
\hline \multirow{4}{*}{} & GenCat & 6.000 \\
\cline { 2 - 3 } & GenCat & 2.000 \\
\cline { 2 - 3 } & GenCat & 82.776 \\
\cline { 2 - 3 } & GenCat & 710.438 \\
\cline { 2 - 3 } & GenCat & 9.979 \\
\hline 11 & AjBcn & 10.969 \\
\cline { 2 - 3 } & AjBcn & 8.448 \\
\cline { 2 - 3 } & AjBcn & 2.771 \\
\cline { 2 - 3 } & GenCat & 800.000 \\
\hline 12 & AjBcn & 750.000 \\
\hline
\end{tabular}

\subsection{Resultados de evaluación de una muestra de entidades}

Una vez identificadas las entidades que están obligadas a cumplir con la Ley de Transparencia y las que también podrían o no estar obligadas, dependiendo de las ayudas recibidas y del porcentaje que estas supongan de su presupuesto anual, hemos determinado una muestra para ver hasta qué punto se cumple con esta obligación.

Como hay una cantidad significativa de entidades que reciben ayudas por encima de $100.000 €$, empezamos a hacer un test de evaluación con estas. Los resultados del test fueron tan bajos que decidimos continuar trabajando con estas entidades, porque son las primeras obligadas a cumplir y a ser ejemplo para el resto, es decir, las que reciben subvenciones de menos importancia. Así, hemos trabajado con las 55 entidades que reciben las ayudas más altas, por encima de 200.000€. La Tabla 11 muestra los resultados de las evaluaciones de cada entidad y la Tabla 12 ofrece los datos más destacados.

Hay que señalar que 5 de estas entidades no disponen de una sede electrónica que les permita publicar las informaciones y que ninguna entidad llega a tener un $40 \%$ de indicadores validados. Muchas de las páginas evaluadas son espacios de difusión donde no hemos encontrado algunas de las informaciones más elementales, y la evaluación ha tenido como resultado que la media de indicadores validados ha sido 7 y la media de porcentaje de validación de indicadores solo del 16,8\%.

Por otra parte, no hay una clara correlación de mayor o menor validación de indicadores que se pueda relacionar directamente con las cuantías de los recursos obtenidos. Hay que ir hasta el puesto 14 para encontrar a la entidad que tiene los resultados más altos. Entre las tres primeras hay una que no dispone de web y entre las cinco primeras una que solo cumple con tres indicadores.

Por último, no se puede encontrar ninguna relación positiva entre las tipologías jurídicas de las entidades o el sector de actividad y una puntuación más alta. 
Tabla 11. Resultados de las evaluaciones

\begin{tabular}{|c|c|c|c|}
\hline Orden & Importe total & $\begin{array}{c}\text { Indicadores } \\
\text { validados }\end{array}$ & $\begin{array}{c}\% \\
\text { evaluación }\end{array}$ \\
\hline 1 & 3.305 .617 & 9 & 20,5 \\
\hline 2 & 3.080 .000 & 15 & 33,3 \\
\hline 3 & 1.656 .688 & 0 & 0,0 \\
\hline 4 & 1.377 .213 & 16 & 36,4 \\
\hline 5 & 1.324 .543 & 3 & 6,7 \\
\hline 6 & 1.007 .677 & 7 & 15,6 \\
\hline 7 & 996.535 & 7 & 15,9 \\
\hline 8 & 947.312 & 6 & 13,3 \\
\hline 9 & 927.042 & 5 & 11,1 \\
\hline 10 & 826.126 & 10 & 22,2 \\
\hline 11 & 822.188 & 14 & 31,1 \\
\hline 12 & 750.000 & 9 & 20,5 \\
\hline 13 & 668.951 & 7 & 15,6 \\
\hline 14 & 590.278 & 17 & 37,8 \\
\hline 15 & 571.135 & 9 & 20 \\
\hline 16 & 531.242 & 7 & 15,9 \\
\hline 17 & 529.410 & 8 & 18,2 \\
\hline 18 & 508.000 & 5 & 11,1 \\
\hline 19 & 482.870 & 5 & 11,1 \\
\hline 20 & 480.000 & 8 & 18,2 \\
\hline 21 & 479.334 & 2 & 4,4 \\
\hline 22 & 475.685 & 4 & 9,1 \\
\hline 23 & 457.200 & 6 & 13,6 \\
\hline 24 & 443.982 & 6 & 13,6 \\
\hline 25 & 438.700 & 4 & 8,9 \\
\hline 26 & 400.000 & 4 & 9,1 \\
\hline 27 & 386.390 & 4 & 9 \\
\hline 28 & 370.601 & 10 & 22,2 \\
\hline 29 & 358.020 & 14 & 31,9 \\
\hline 30 & 339.045 & 2 & 4,5 \\
\hline 31 & 320.713 & 6 & 13,6 \\
\hline 32 & 317.056 & 4 & 8,9 \\
\hline 33 & 313.150 & 10 & 22,2 \\
\hline 34 & 312.942 & 10 & 22,7 \\
\hline 35 & 306.910 & 13 & 28,9 \\
\hline 36 & 304.311 & 13 & 29,5 \\
\hline 37 & 299.842 & 7 & 15,6 \\
\hline 38 & 293.891 & 10 & 22,7 \\
\hline 39 & 278.658 & 7 & 15,6 \\
\hline
\end{tabular}




\begin{tabular}{|r|r|r|r|}
\hline 40 & 271.458 & 11 & 25,0 \\
\hline 41 & 269.273 & 0 & 0,0 \\
\hline 42 & 259.109 & 0 & 0,0 \\
\hline 43 & 257.298 & 10 & 22,7 \\
\hline 44 & 256.208 & 0 & 0,0 \\
\hline 45 & 251.717 & 3 & 6,7 \\
\hline 46 & 250.750 & 5 & 11,1 \\
\hline 47 & 250.000 & 8 & 18,2 \\
\hline 48 & 245.000 & 6 & 13,3 \\
\hline 49 & 236.750 & 4 & 9,1 \\
\hline 50 & 229.877 & 7 & 15,6 \\
\hline 51 & 224.752 & 12 & 26,7 \\
\hline 52 & 221.035 & 2 & 4,5 \\
\hline 53 & 220.508 & 7 & 15,6 \\
\hline 54 & 220.000 & 0 & 0,0 \\
\hline 55 & 216.053 & 8 & 18,2 \\
\hline
\end{tabular}

*En amarillo, las entidades sin web

Tabla 12. Resumen de las evaluaciones

\begin{tabular}{|l|r|}
\hline Fundaciones evaluadas & 26 \\
\hline Asociaciones evaluadas & 13 \\
\hline Federaciones evaluadas & 10 \\
\hline Cooperativas evaluadas & 3 \\
\hline Entidades religiosas evaluadas & 2 \\
\hline Consejos deportivos escolares evaluados & 1 \\
\hline \multicolumn{2}{|c|}{} \\
\hline Entidades sin web & 7,0 \\
\hline $\begin{array}{l}\text { Número medio de indicadores validados, excluyendo entidades } \\
\text { sin web }\end{array}$ & 16,8 \\
\hline $\begin{array}{l}\text { Porcentaje medio de cumplimiento, excluyendo entidades sin } \\
\text { web }\end{array}$ & $17 / 37,8 \%$ \\
\hline $\begin{array}{l}\text { Número de indicadores y porcentaje de la entidad con mejores } \\
\text { resultados (14) }\end{array}$ & \\
\hline
\end{tabular}

\section{Conclusiones y propuestas}

El estudio demuestra que el procedimiento que tiene que seguir el Ayuntamiento de Barcelona para saber cuándo una entidad está obligada a cumplir con la Ley de Transparencia es complicado, pues requiere de varios pasos, como la comprobación de las ayudas otorgadas por diferentes administraciones y su posterior suma, además de la verificación de que la entidad está cumpliendo dicha obligación.

El análisis de la "Convocatoria General" anual de subvenciones se ha demostrado insuficiente, porque el Ayuntamiento de Barcelona otorga ayudas a las 
entidades por otras vías y porque estas pueden recibir otras subvenciones de diferentes administraciones públicas. Así, si bien en la convocatoria de subvenciones para actuaciones de ciudad y distrito se concedieron 5 ayudas de más de $100.000 €$ y 370 de entre 5.000 y 100.000€, el estudio del conjunto de subvenciones y ayudas para entidades no lucrativas, eleva estas cantidades a 72 de más de $100.000 €$ y 806 de más de 5.000€. Como se puede ver, de las 3.195 ayudas económicas estudiadas, aunque en esa convocatoria general se adjudicaron 1.831, estas no han sido la parte mayoritaria de las más elevadas en ninguna de las dos franjas estudiadas.

Por otra parte, hemos constatado la necesidad de agrupar los diferentes importes concedidos a cada entidad por la misma institución y por el conjunto de las distintas administraciones públicas. La suma de estos importes ha permitido ver que 794 entidades, el 42,6\% de las que reciben alguna subvención, obtienen financiación por encima de 5.000€ y, de estas, 101 superan los 100.000€. Además, hemos comprobado también que algunas entidades reciben una financiación muy pequeña del Ayuntamiento de Barcelona, a veces incluso inferior a $1.000 €$, pero que reciben a la vez cantidades muy elevadas de la Generalitat de Cataluña. Solo haciendo esta agrupación se ha podido ver que entidades subvencionada con menos de 5.000€ por el Ayuntamiento de Barcelona, obtienen financiación de otra administración por encima de $100.000 €$ y que, por lo tanto, están obligadas a cumplir con la Ley de Transparencia.

El análisis también demuestra que el Ayuntamiento de Barcelona concede anualmente una cantidad significativa de ayudas y subvenciones a entidades que deben cumplir con las obligaciones de transparencia (794 ayudas). En este sentido, sería conveniente que procurara que el conjunto de las entidades subvencionadas, como perceptoras de recursos públicos, incorporaran el valor de la transparencia como un rasgo distintivo.

Los resultados de las evaluaciones no han alcanzado en ningún caso la mitad de los indicadores de cumplimiento y por ello ni siquiera se ha podido establecer una relación clara entre las características de las entidades y los resultados-

En cambio, si podemos señalar que de esas 55 entidades analizadas, que reciben subvenciones y/o ayudas públicas de más de 200.000€ en una única anualidad y que llegan a recibir hasta más de 3.000.000€ en dos casos, más de 1.000.000€ en 4 casos y más de medio millón de euros en 12 oportunidades más, casi el 50\% (26 de 55) son Fundaciones. Igualmente, detectamos que en convocatoria general anual de subvenciones del Ayuntamiento de Barcelona, de las 5 únicas subvenciones concedidas de más de $100.000 €$, 4 se otorgaron a entidades del sector deporte, tan solo 1 en el sector cultura, mientras que en el resto de ámbitos de la convocatoria no se concede ninguna que alcance esa cantidad.

Aunque el seguimiento del cumplimiento de la Ley debe aplicarse a todas las entidades por igual, estos datos señalan algunos campos de atención específicos a los que convendría hacer un seguimiento concreto, tanto desde el punto de vista de la investigación académica, como desde el de las administraciones públicas que otorgan estos recursos económicos y por parte de los garantes de la Ley. Cabe recordar que en la gestión de las Fundaciones, por su naturaleza jurídica, no caben ni socios ni 
accionistas, por lo que el deber de transparencia es imprescindible. La importancia de esta cuestión está recogida en la Ley 21/2014, de 29 de diciembre, del protectorado de las fundaciones y de verificación de la actividad de las asociaciones declaradas de utilidad pública ${ }^{16}$ de Cataluña, cuyo Capítulo II, Transparencia, determina en su articulado, entre otras consideraciones a los sujetos responsables y la información que debe ser publicada, complementando lo ya dispuesto en la Ley de Transparencia de Cataluña. Consideramos que un nivel de cumplimiento por debajo del $50 \%$ no se debe sólo a dificultades de interpretación del texto legal. También se deben considerar otros factores como la falta de tradición y de conocimientos. En muchos casos también de recursos, pero consideramos que las entidades que reciben las subvenciones más altas, las que han sido evaluadas en este estudio, no pueden argumentar esta falta de capacidad.

Estos resultados contrastan con los recursos existentes para sensibilizar y formar a las entidades sobre cuáles son sus obligaciones. Por ahora, los esfuerzos realizados por el Ayuntamiento de Barcelona, y también por diferentes organismos de la Generalitat de Catalunya, no han tenido los resultados esperados.

Tras el análisis de estos resultados, consideramos imprescindible que el Ayuntamiento de Barcelona establezca un procedimiento para que tanto la propia administración como las entidades que reciben ayudas y subvenciones conozcan los importes totales concedidos anualmente y sean conscientes de las obligaciones que conllevan. También es necesario instar al resto de las administraciones responsables a elaborar un archivo único de subvenciones y ayudas públicas para saber qué entidades tienen obligaciones.

Asimismo, estimamos que se debe continuar por el camino de sensibilizar a los órganos directivos de las entidades, formar a los responsables de comunicación y ofrecer recursos que faciliten la aplicación, hasta conseguir que un grupo significativo de entidades cumplan y sean referentes para al resto.

Este grupo de entidades debería recibir también algunas señales motivadoras. Por un lado, destacando las buenas prácticas y, por otro, estableciendo un mecanismo de contacto permanente para que entiendan la necesidad de ser transparentes y los beneficios que les comportará incorporar este valor y las prácticas que se derivan. Para ello habría que hacerles un asesoramiento directo y continuado, así como disponer de un espacio de seguimiento de buenas prácticas.

Por último, destacamos que si resulta muy difícil para el Ayuntamiento de Barcelona tanto saber qué entidades perceptoras de subvenciones de entre $5.000 \mathrm{y}$ $100.000 €$ deben cumplir con la Ley de Transparencia (ya que las cantidades recibidas deben suponer al menos el $40 \%$ de su presupuesto anual), como evaluar el cumplimiento en todos los casos, podemos formular como hipótesis para futuros trabajos que el resto de ayuntamientos de España tienen los mismos problemas. Si incluso para una gran administración como el Ayuntamiento de Barcelona, hacer este seguimiento requiere de una dedicación especializada y continuada, en el caso de los

16 Ley 21/2014, de 29 de diciembre, del protectorado de las fundaciones y de verificación de la actividad de las asociaciones declaradas de utilidad pública (BOE núm 18, de 21 de enero de 2015), BOE en http://www.boe.es/diario_boe/txt.php?id=BOE-A-2015-472 
ayuntamientos de menor envergadura cabe suponer que resultará aún más complicado contar con los recursos económicos y humanos necesarios para poder hacerlo.

Proponemos que la solución a este problema se aborde también desde la colaboración institucional y el impulso de sinergias, propiciando un acercamiento global y facilitador de recursos y soluciones para las propias administraciones y para las entidades afectadas, contando con la participación de servicios y personal especializado, así como con la creación de bases de información unificadas y abiertas $^{17}$.

\section{Referencias bibliográficas}

Álvarez Espinar, M. (2014). Apertura y reutilización de datos públicos (Obertura i reutilització de dades publiques). Barcelona: Generalitat de Catalunya, Direcció General d'Atenció Ciutadana i Difusió.

Arredondo Trapero, F. G.; Garza García, J. de la; \& Vázquez Parra, J. C. (2014). Transparencia en las organizaciones, una aproximación desde la perspectiva de los colaboradores. Estudios Gerenciales, 30, 408-418. doi: 10.1016/j.estger.2014.06.007.

Arroyo-Almaraz, I.; Baladrón-Pazos, A.; \& Martín-Nieto, R. (2013). La comunicación en redes sociales: percepciones y usos de las ONG españolas. Cuadernos de Información, 32, 77-88. http://dx.doi.org/10.7764/cdi.32.497.

Baamonde-Silva, X.; Martínez-Rolán, X.; \& Míguez-González, M. I. (2016). Las ONG como agentes de transformación social. Del asistencialismo a la movilización. OBETS. Revista de Ciencias Sociales, 11 (1), 53-74. http://dx.doi.org/10.14198/ OBETS2016.11.1.04.

Baamonde-Silva, X. M.; García-Mirón, S. y Martínez-Rolán, X. (2017). Solidaridad y transparencia digital. Webs y redes sociales de las ONGS españolas de acción social. El profesional de la información, 26 (3), 438-446. doi: 10.3145/epi.2017.may.10.

Barranquero-Carretero, A. (2014). Comunicación, cambio social y ONG en España. Pistas para profundizar en la cultura de la cooperación desde los nuevos movimientos comunicacionales. El caso del 15M. COMMONS - Revista de Comunicación y Ciudadanía Digital. 3 (1), 6-34.

Burger, R., \& Owens, T. (2010). Promoting Transparency in the NGO Sector: Examining the Availability and Reliability of Self-Reported Data. World Development, 38 (9), 1263-1277. doi: 10.1016/j.worlddev.2009.12.018.

Coordinadora de ONG para el Desarrollo - España (2012). Indicadores de Transparencia y buen gobierno (versión ONGD). Madrid: Publicaciones Coordinadora. Disponible en http://webtransparencia.coordinadoraongd.org/wpcontent/uploads/Herramienta_Transpa rencia_y_Buen_Gobierno_Rev_Marzo_20121.pdf Consulta: 23/03/2018].

Darnton, A., \& Martin, K. (2011). Finding frames: New ways to engage the UK public in global poverty. London: Oxfam.

Dopazo, M. P. (2012). Informes de Responsabilidad Social Corporativa (RSC): Fuentes de Información y Documentación. Revista General de Información y Documentación, 22, 279-305. doi: 10.5209/rev_RGID.2012.v22.39666.

17 Esta investigación se ha realizado en el marco del proyecto Informe sobre el estado de la transparencia de las entidades que reciben subvenciones del Ayuntamiento de Barcelona (2016), financiado por el Ayuntamiento de Barcelona. 
Edelman. (2015). 2015 Edelman Trust Barometer. Disponible en: https://www.edelman.com/insights/intellectual-property/2015-edelman-trust-barometer/ [Consulta: 22/11/17].

Edelman. (2017). 2017 Edelman Trust Barometer. Disponible en: https://www.edelman.com/trust2017/ [Consulta: 13/11/17].

Fernández, R. \& Ospina, R. I. (2012). Manual de autoevaluación sobre las prácticas de transparencia y rendición de cuentas. Iniciativa Regional de la sociedad Civil: Rendir Cuentas. Disponible en http://rendircuentas.org/AplicacionRendirCuentas/index.html [Consulta: 23/03/2018].

Fernández Ramos, S. \& Pérez Monguió, J.M. (2014). Transparencia, acceso a la información pública y buen gobierno. Pamplona: Editorial Aranzadi.

Fernández Torres, M. J. (2013). Gestión de la comunicación en el sector no lucrativo español. Revista de Comunicación de la SEECI, XVII (30), 94-105. doi: 10.15198/seeci.2013.30.94-105.

Gálvez-Rodríguez, M. M.; Caba-Pérez, C.; \& López-Godoy, M. (2016). NGOs efficiency and transparency Policy: the Colombian Case. Innovar, 26 (60), 67-82. http://dx.doi.org/10.15446/innovar.v26n60.55534.

García-López, M. (2012). Repensar la comunicación para la paz y la solidaridad desde lo participativo. Claves y propuestas. Razón y palabra, 81.

Gaventa, J., \& McGee, R. (2013). The Impact of Transparency and Accountability Initiatives. Development Policy Review, 31 (1), s3-s28. doi: 10.1111/dpr.12017.

Herranz de la Casa, J. M. (2007). La gestión de la comunicación como elemento generador de transparencia en las organizaciones no lucrativas. Revista de Economía Publica, Social y Cooperativa, 57 (abril), 5-31.

LaPorte, T. M.; Demchak, C. C.; \& DeJong, M. (2002). Democracy and bureaucracy in the age of the Web. Administration \& Society, 34 (4), 411-446. doi: 10.1177/0095399702034004004.

Martín Pérez, V., \& Martín Cruz, N. (2017). La web como mecanismo de transparencia de las ONG. Más allá de la certificación. Revista Española del Tercer Sector, 37 (cuatrimestre III), 159-190.

Martínez-Martínez, I. (coord.) (2011). Renovando el papel de las ONGD. Hacia la transformación social. Madrid: Plataforma 2015 y más.

Messeguer Yebra, J. (2014). Comentario a Ley 19/2013, de 9 de diciembre, de transparencia, acceso a la información pública y buen gobierno. Granada: Centro de Estudios Municipales y de Cooperación Internacional.

Molina Rodríguez-Navas, Pedro (2017). Criterios y herramientas para la transparencia de las entidades sin ánimo de lucro. En Linares Herrera, Manuel; Díaz Cuesta, José; del Valle Mejías, M ${ }^{\mathrm{a}}$ Elena (Coord.), Innovación universitaria: digitalización 2.0 y excelencia en contenidos, Madrid: McGraw Hill, pp.571-577.

Molina Rodríguez-Navas, Pedro (2014). Transparència i qualitat de la informació de les entitats sense ànim de lucre. Manual i guia d'autoavaluació. Ajuntament de Barcelona, Universitat Autònoma de Barcelona. Disponible en: http://transpar-ent.info/wpcontent/uploads/2016/02/Guia-autoavaluacio-ESAL-LPCCP-UAB.pdf. [Consulta: 23/03/2018].

Molina, P.; Simelio, N.; \& Corcoy, M. (2017). Metodologías de evaluación de la transparencia: procedimientos y problemas. Revista Latina de Comunicación Social, 72, 818-831. http://dx.doi.org/10.4185/RLCS-2017-1194. 
Moreno, A.; Molina, P. \& Simelio, N. (2017). Impacto de la Legislación Sobre Transparencia en la Información Publicada por las Administraciones Locales. El profesional de la información, 26 (3), 370-380. doi: 10.3145/epi.2017.may.03.

Navajo-Gómez, P. (2009). Planificación estratégica en organizaciones no lucrativas. Guía participativa basada en valores. Madrid: Narcea Ediciones

Nos-Aldás, E., \& Santolino-Prieto, M. (2015). La Investigación en Comunicación y Cooperación en los nuevos escenarios de movilización social: ONGD, objetivos de justicia social y eficacia cultural. Revista de la Asociación Española de Investigación de la Comunicación, 2 (4), 1-7.

Santolino-Prieto, M. (2010). Recuperando la esencia: las ONGD como agentes de comunicación para el cambio social. In T. Burgui-Jurío \& J. Erro-Sala (eds.). Comunicando para la solidaridad y la cooperación: cómo salir de la encrucijada. Pamplona: Foro Comunicación, Educación y Ciudadanía, 221-256.

Szper, R., \& Prakash, A. (2011). Charity watchdogs and the limits of information-based regulation. Voluntas, 22 (1), 112-141. doi: 10.1007/s11266-010-9156-2.

Valls, N. (2010). La transparència i la rendició de comptes al tercer sector. Reflexió i autodiagnòstic. Barcelona: Observatori del Tercer Sector. Disponible en http://governacio.gencat.cat/web/.content/qualitat_democratica/08_qd_i_associacions/ar xius/transparencia.pdf [Consulta: 23/03/2018].

Vargas Díaz, C.D. (2011). La globalización del e-gobierno y la transparencia de la información pública. Collado Villalba, Madrid: Delta Publicaciones.

Villoria Mendieta, M. (2014). La publicidad activa en la Ley de transparencia, acceso a la información y buen gobierno: posibilidades e insuficiencias. Barcelona: Generalitat de Catalunya, Direcció General d'Atenció Ciutadana i Difusió.

Wences, I; Kölling, M \& Ragone, S. (coords.) (2014) La Ley de Transparencia, Acceso a la Información Pública y Buen Gobierno. Una perspectiva acadèmica. Madrid: CEPC. 